\title{
Enhanced Firing in NTS Induced by Short-Term Sustained Hypoxia Is Modulated by Glia-Neuron Interaction
}

\author{
Daniela Accorsi-Mendonça, Carlos E.L. Almado, Leni G.H. Bonagamba, Jaci A. Castania, Davi J.A. Moraes, \\ and Benedito H. Machado \\ Department of Physiology, School of Medicine of Ribeirão Preto, University of São Paulo, 14049-900Ribeirão Preto, SP, Brazil
}

\begin{abstract}
Humans ascending to high altitudes are submitted to sustained hypoxia (SH), activating peripheral chemoreflex with several autonomic and respiratory responses. Here we analyzed the effect of short-term SH $\left(24 \mathrm{~h}, \mathrm{FIO}_{2} 10 \%\right)$ on the processing of cardiovascular and respiratory reflexes using an in situ preparation of rats. SH increased both the sympatho-inhibitory and bradycardiac components of baroreflex and the sympathetic and respiratory responses of peripheral chemoreflex. Electrophysiological properties and synaptic transmission in the nucleus tractus solitarius (NTS) neurons, the first synaptic station of afferents of baroreflexes and chemoreflexes, were evaluated using brainstem slices and whole-cell patch-clamp. The second-order NTS neurons were identified by previous application of fluorescent tracer onto carotid body for chemoreceptor afferents or onto aortic depressor nerve for baroreceptor afferents. SH increased the intrinsic excitability of NTS neurons. Delayed excitation, caused by A-type potassium current $\left(\mathrm{IK}_{\mathrm{A}}\right)$, was observed in most of NTS neurons from control rats. The $\mathrm{IK}_{\mathrm{A}}$ amplitude was higher in identified second-order NTS neurons from control than in SH rats. SH also blunted the astrocytic inhibition of $\mathrm{IK}_{\mathrm{A}}$ in NTS neurons and increased the synaptic transmission in response to afferent fibers stimulation. The frequency of spontaneous excitatory currents was also increased in neurons from SH rats, indicating that $\mathrm{SH}$ increased the neurotransmission by presynaptic mechanisms. Therefore, short-term SH changed the glia-neuron interaction, increasing the excitability and excitatory transmission of NTS neurons, which may contribute to the observed increase in the reflex sensitivity of baroreflex and chemoreflex in in situ preparation.
\end{abstract}

Key words: astrocytes; firing; intrinsic properties; NTS; sustained hypoxia; synaptic transmission

\section{Introduction}

Experimental hypoxic condition induces activation of peripheral chemoreflex, which increases sympathetic activity, blood pressure, and ventilation (Antunes et al., 2005; Moraes et al., 2011). Similar changes were also observed in unacclimatized humans after ascending to high altitude (Basu et al., 1996; Hackett and Roach, 2001; Roach and Hackett, 2001). These responses are due to the activation of glomus cells located in carotid body, which are $\mathrm{pO}_{2}$-sensitive, in close contact with afferents of peripheral chemoreceptors (McDonald, 1983). The peripheral chemoreceptors afferents establish synaptic contact with second-order neurons in nucleus tractus solitarius (NTS), via tractus solitarius (TS; Donoghue et al., 1984; Claps and Torrealba, 1988; Mifflin, 1992; Chitravanshi and Sapru, 1995). After integrating signals from sensorial inputs, the NTS neurons of chemoreflex pathways

\footnotetext{
Received Nov. 6, 2014; revised March 6, 2015; accepted March 20, 2015.

Author contributions: D.A.-M., C.E.L.A., D.J.A.M., and B.H.M. designed research;D.A.-M., C.E.L.A., L.G.H.B., J.A.C., D.J.A.M., and B.H.M. performed research; D.A.-M., C.E.L.A., D.J.A.M., and B.H.M. analyzed data; D.A.-M., D.J.A.M., and B.H.M. wrote the paper.

This work was supported by FAPESP Grants 2009/50113-0 and 2013/06077-5, CNPQ Grant 472704/04-4, and FAPESP fellowship Grant 2011/24050-1 to D.J.A.M. We thank Ricardo M. Leão for his comments and suggestions.

The authors declare no competing financial interests.

Correspondence should be addressed to Dr Daniela Accorsi-Mendonça, Department of Physiology, School of

Medicine of Ribeirão Preto, University of São Paulo, Av. Bandeirantes, 3900, 14049-900, Ribeirão Preto, SP, Brazil. E-mail: daniaccorsi@usp.br.

DOI:10.1523/JNEUROSCI.4598-14.2015

Copyright $\odot 2015$ the authors $\quad 0270-6474 / 15 / 356903-15 \$ 15.00 / 0$
}

send projections to several other brain areas (brainstem, pons, hypothalamus, and cortex) to provide autonomic, respiratory, and behavioral adjustments to the hypoxic challenge (AccorsiMendonça and Machado, 2013).

Short-term sustained hypoxia ( $\mathrm{SH}$ ) for $24 \mathrm{~h}$ produces an increase in arterial pressure and expiration in rats (Moraes et al., 2014). SH also induces several adaptive changes in peripheral chemoreflex pathways, such as, enhancement of gene transcription and excitability of glomus cells in carotid body (Wang et al., 2000; Ortiz et al., 2009; Liu et al., 2013). Long-term SH for $10 \mathrm{~d}$ also affected NTS neurons, which presented an increased NTS neuronal discharge due to an evoked excitatory inputs to NTS neurons, as well as a decrease in $\mathrm{K}_{\mathrm{ATP}}$ channel subunits expression (Kir 6.1 and Kir 6.2 subunits; Zhang et al., 2008, 2009. Furthermore, episodes of chronic intermittent hypoxia (CIH) also change the NTS synaptic plasticity, because there is a reduction in the afferent glutamatergic neurotransmission in NTS neurons in rats submitted to $\mathrm{CIH}$ (10 d), probably because of a decrease in the number of active synapses, as we previously documented (Almado et al., 2012). All these changes in the NTS neurons may contribute to the observed increase in sympathetic activity and high blood pressure observed in CIH rats (Zoccal et al., 2009).

Although the neural adaptations to sustained hypoxia was previously documented (Zhang et al., 2008 and 2009), the mechanisms underlying the synaptic response of NTS neurons to short-term SH and the functional implications of these changes 
are not yet fully understood. Here, we evaluated the changes in baroreflexes and chemoreflexes sensitivity using: (1) an in situ preparation of rats submitted to short-term SH $\left(24 \mathrm{~h}, 10 \% \mathrm{O}_{2}\right)$ and (2) whole-cell patch-clamp in brainstem slices. A fine electrophysiological approach was used to explore the effects of $\mathrm{SH}$ on intrinsic properties and synaptic transmission of secondorder NTS neurons receiving afferent inputs from baroreceptors and chemoreceptors. The overall changes observed in NTS neurons of $\mathrm{SH}$ rats might explain at least in part, the multiple and complex neurovegetative dysfunctions associated to the mountain sickness.

\section{Materials and Methods}

The experimental protocols used in the present study were approved by the Institutional Ethical Committee on Animal Experimentation of the School of Medicine of Ribeirão Preto, University of São Paulo (Protocols CEUA: 019/2006, 070/2007, 064/2010).

$\mathrm{SH}$ model. Experiments were performed in 55 juvenile male Wistar rats (21- to 30-d-old), which were divided into two groups: (1) rats exposed to $\mathrm{SH}\left(\mathrm{FIO}_{2}: 10 \%\right)$ for $24 \mathrm{~h}$ and (2) rats maintained under normoxic condition $\left(\mathrm{FIO}_{2}: 21 \%\right)$. Rats were maintained inside of acrylic chambers equipped with gas injectors and sensors for $\mathrm{O}_{2}, \mathrm{CO}_{2}$, humidity, and temperature inside the chamber (Oxycylcer, Biospherix) and had access to food and water ad libitum. The room temperature was kept at $23 \pm 2^{\circ} \mathrm{C}$ with a $12 \mathrm{~h}$ dark/light cycle.

Labeling of baroreceptor and chemoreceptor inputs to the NTS with fluorescent tracer (DiI). We used a fluorescent membrane tracer [1'dioctadecyl-3,3,3',3'-tetramethylindocarbocyanine perchlorate (DiI, Invitrogen)] to identify the second-order NTS neurons that received baro- or chemoreceptor inputs. For this purpose, we applied the DiI onto aortic depressor nerve (ADN) fibers or carotid body $(\mathrm{CB})$ as previously described by Accorsi-Mendonça et al. (2009). Briefly, animals were anesthetized with intraperitoneal injection of ketamine $\left(0.6 \mathrm{mg} \mathrm{kg}^{-1}\right.$, União Química Farmacêutica Nacional S/A) + xylasine $\left(0.6 \mathrm{mg} \mathrm{kg}^{-1}\right.$, União Química Farmacêutica Nacional S/A) and divided into two groups of rats: (1) tracer applied onto ADN and (2) tracer applied onto CB. During the surgery, the DiI crystals were gently applied bilaterally onto the $\mathrm{CB}$ or ADN fibers and they were coated with silicone elastomer (Kwik-Sil, WPI). One week after this surgery, rats were submitted to the SH or control condition during $24 \mathrm{~h}$. At the end of this protocol, slices of brainstem were obtained to in vitro experiments.

In situ preparation. Immediately after of $24 \mathrm{~h}$ of $\mathrm{SH}$ experimental protocols, rats were prepared for the in situ Working Heart Brainstem Preparation (WHBP), as previously described (Paton, 1996; Moraes et al., 2013). Rats were deeply anesthetized with halothane (Astra Zeneca), transected caudal to the diaphragm, exsanguinated and submerged in a cooled Ringer solution (in mu: $125 \mathrm{NaCl}, 24 \mathrm{NaHCO}_{3}, 3 \mathrm{KCl}, 2.5 \mathrm{CaCl}_{2}$, $1.25 \mathrm{MgSO}_{4}, 1.25 \mathrm{KH}_{2} \mathrm{PO}_{4}, 10$ dextrose). They were then decerebrated at the precollicular level, therefore rendered insentient, and skinned. The descending aorta was isolated and the lungs removed. Preparations were then transferred to a recording chamber and the descending aorta was cannulated with a double-lumen cannula and retrogradely perfused with Ringer's solution containing an oncotic agent (1.25\% polyethylene glycol, Sigma-Aldrich) and a neuromuscular blocker (vecuronium bromide, 3-4 $\mu \mathrm{g} / \mathrm{ml}$, Cristália Produtos Químicos Farmacêuticos) using a peristaltic pump (Watson-Marlow $502 \mathrm{~s}$, Falmouth). The mean perfusion pressure was maintained in the range $50-70 \mathrm{mmHg}$ by adjusting the flow between 21 and $25 \mathrm{ml} / \mathrm{min}$ and by adding vasopressin $(0.6-1.2 \mathrm{nM}$, Sigma-Aldrich) to the perfusate, which was continuously gassed with $5 \%$ $\mathrm{CO}_{2}$ and $95 \% \mathrm{O}_{2}$ (White Martins), warmed to $31-32^{\circ} \mathrm{C}$ and filtered using a nylon mesh (pore size: $25 \mu \mathrm{m}$, Millipore).

Electrophysiological data acquisition. Sympathetic and respiratory motor nerves were isolated and recorded using bipolar glass suction electrodes with the aid of a micromanipulator (Narishige). Phrenic nerve (PN) activity was recorded from its central end. The activity of thoracic sympathetic nerve ( $\mathrm{tSN}$ ) was recorded from the sympathetic chain at the level of $\mathrm{T} 8-\mathrm{T} 12$. Abdominal nerve $(\mathrm{AbN})$ was isolated from the abdominal muscles at thoracic-lumbar level, cut distally, and its activity re- corded. Heart rate (HR) was derived from ECG. All signals were amplified, bandpass filtered $(0.05-5 \mathrm{kHz})$, and digitized $(5 \mathrm{kHz}$; CED Micro1401; Cambridge Electronic Design; CED) to a computer using Spike2 software v5 (CED).

Chemoreflex and baroreflex activation in in situ preparations. Peripheral chemoreceptors were stimulated by injections of potassium cyanide ( $\mathrm{KCN} 0.05 \%, 50 \mu \mathrm{l})$ into the descending aorta of the in situ preparations via the perfusion cannula as previously described (Moraes et al., 2012). The sympatho-inhibitory and bradycardic responses to electrical stimulation of the $\mathrm{ADN}(0.2 \mathrm{~ms}, 3$ pulses at $400 \mathrm{~Hz})$ were used as an index of barosensitivity. The stimulus intensity was set at the intensity required to elicit a fall in the perfusion pressure $>10 \mathrm{mmHg}$ in response to ADN stimulation at $50 \mathrm{~Hz}$ ( $0.2 \mathrm{~ms}$ duration) for $5 \mathrm{~s}$ (threshold), as described by Moraes et al. (2012).

Data analysis of in situ preparations. The quantification of the sympathetic, bradycardic and respiratory responses to chemoreflex activation was performed in accordance with a previous description by Moraes et al. (2012). PN inspiratory response to chemoreflex activation was assessed by the difference between baseline PN burst frequency and the peak of response observed after the stimulus ( $\triangle \mathrm{PN}$, expressed in $\mathrm{Hz}$ ). The tSN (during inspiration and expiration) and $\mathrm{AbN}$ expiratory responses to peripheral chemoreflex activation was assessed by the measurement of the area under the curve, in a time window of $\leq 10 \mathrm{~s}$ after the stimulus, and expressed as percentage values ( $\Delta \mathrm{tSN}$ and $\Delta \mathrm{AbN}$ in percentage) in relation to the activity before the stimulus. To evaluate the barosensitivity of $\mathrm{tSN}$, we compared the reduction in the $\mathrm{tSN}$ activity during the ADN stimulus with an average of the $\mathrm{tSN}$ activity recorded during 10 respiratory cycles immediately preceding the stimulus. We calculated the area under the integrated activities of tSN and the ratio of the tSN activity between stimulation and the control condition was calculated as follows and used as an index of barosensitivity: percentage of inhibition = [(baseline $\mathrm{tSN}$ activity - tSN activity during stimulus)/baseline $\mathrm{tSN}$ activity] $\times 100$. The HR responses $(\Delta \mathrm{HR})$ to chemoreflex and baroreflex activation were quantified by measuring the maximum bradycardia. We calculated the intensity required to produce $50 \%$ of inhibition of tSN and $\mathrm{HR}$ to ADN stimulation by fitting the responses to different intensities (threshold, two-, three-, and fourfold the threshold) using the following logistic equation (GraphPad Prism v4): $Y=a 1(a 2-\mathrm{a} 1) / 1+10(\log x 0-$ $x) p$, in which $a 1$ is the minimal response; $a 2$ is the maximum response; $\log (x 0-x)$ : correspond to $50 \%$ of inhibition and $p$ is the slope.

Data were compared using one-way ANOVA with Tukey post hoc testing or a Student's unpaired $t$ test (GraphPad Prism) in accordance with the experimental protocol. Differences were considered significant at $p<0.05$.

Brainstem slice preparation. At the end of the $24 \mathrm{~h}$ protocols of $\mathrm{SH}$ or control conditions the rats were decapitated and the brain was rapidly removed and submerged in modified ice-cold $\left(4^{\circ} \mathrm{C}\right)$ artificial CSF (aCSF) containing the following (in $\mathrm{mM}$ ): $125 \mathrm{NaCl}, 2.5 \mathrm{KCl}, 1 \mathrm{MgCl}_{2}, 1.25$ $\mathrm{NaH}_{2} \mathrm{PO}_{4}, 25 \mathrm{NaHCO}_{3}, 25$ glucose and $2 \mathrm{CaCl}_{2}$, with osmolality of $\sim 300$ mOsm $/ \mathrm{Kg} . \mathrm{H}_{2} \mathrm{O}$ and $\mathrm{pH} 7.4$ when bubbled with $95 \% \mathrm{O}_{2}$ and $5 \% \mathrm{CO}_{2}$. Brainstem transversal slices ( $250 \mu \mathrm{m}$ thick) were cut using an oscillating slicer (Vibratome 1000 plus, Leica Biosystems) and kept in aCSF at $31^{\circ} \mathrm{C}$ for $30 \mathrm{~min}$. Thereafter the slices were kept at room temperature (RT; $23-25^{\circ} \mathrm{C}$ ) in normal aCSF containing the following (in $\mathrm{mM}$ ): $125 \mathrm{NaCl}$, $2.5 \mathrm{KCl}, 1 \mathrm{MgCl}_{2}, 1.25 \mathrm{NaH}_{2} \mathrm{PO}_{4}, 25 \mathrm{NaHCO}_{3}$. Before recordings, a single slice was submerged into the recording chamber, held in place with a nylon thread, and continuously perfused with aCSF at a flow of $\sim 2-3$ $\mathrm{ml} / \mathrm{min}$ at RT.

Neurons in brainstem slice were visualized using infrared and differential interference contrast (IR-DIC) microscopy (Olympus BX51WI) through a $40 \times$ water-immersion objective (LUMPlain F1-IR, Olympus) and a CCD camera (C7500-50, Hamamatsu).

Whole-cell patch-clamp recordings. Whole-cell recordings were made with patch pipettes pulled from thick-walled borosilicate glass capillaries (Sutter Instruments), using a puller (P-97, Sutter Instruments). The patch pipettes were filled with an internal solution containing the following (in $\mathrm{mm}$ ): 130 Kgluconate, $20 \mathrm{KCl}, 2 \mathrm{Mg}$-ATP, $0.3 \mathrm{Na}$-ATP, 10 $\mathrm{Na}_{2}$ phosphocreatin, 5 EGTA, 10 HEPES, osmolality of $\sim 310 \mathrm{mOsm} / \mathrm{Kg}$. $\mathrm{H}_{2} \mathrm{O}$ and $\mathrm{pH} 7.4$ adjusted with $\mathrm{KOH}$ (Almado et al., 2012). The final 
resistance of pipette ranged from 4 to $8 \mathrm{M} \Omega$. The whole-cell configuration was obtained, signals were acquired using an amplifier (Axopatch 200B, Molecular Devices) connected to a data acquisition system (Digidata 1440A, Molecular Devices), and recorded in a microcomputer using software (Clampex, pClamp v10, Molecular Devices). The data obtained in voltage or current-clamp configuration were low-pass filtered at $2 \mathrm{kHz}$ and sampled at $10 \mathrm{kHz}$, according with Nyquist theorem (sampling theorem). Series resistance $(<30 \mathrm{M} \Omega)$ was checked regularly during the experiments and cells with large variations in series resistances were discarded. The membrane potential $\left(V_{\mathrm{m}}\right)$ of cells were held at $-70 \mathrm{mV}$ (voltage-clamp configuration) and recordings started 5 min after establishing the whole-cell configuration.

Electrophysiological measurements. Hyperpolarizing current (steps of $-12.5 \mathrm{pA}$, from -12.5 to $-50 \mathrm{pA}$ with $2 \mathrm{~s}$ duration) was injected into NTS neuron to calculate the input resistance $\left(R_{\text {input }}\right)$. To evoke action potential, two protocols in current-clamp configuration were used: (1) depolarizing injected current pulses of $12.5 \mathrm{mV}$ with duration of $2 \mathrm{~s}$ from the resting membrane potential (holding current $0 \mathrm{pA}$ ) and (2) electrical stimulation of ipsilateral TS fibers $(0.1 \mathrm{~ms}$ duration, $0.07 \mathrm{~Hz})$ from the resting membrane potential (holding current $0 \mathrm{pA}$ ) using a concentric bipolar microelectrode (Frederick Haer) connected to an isolated stimulator (DS2A, Digitimer). The intensity of stimulation was selected using the voltage-clamp configuration. In this case, we increased the intensity of the stimulus to achieve the maximum current amplitude for each recorded neuron and then this intensity of stimulation was used to induce action potentials (Accorsi-Mendonça et al., 2011).

The transient outward potassium current (TOC) was induced using protocols described previously by Bailey et al. (2002). The TOC activation was assessed by conditioning step $(-90 \mathrm{mV}, 500 \mathrm{~ms})$, followed by longer activation steps (from -100 to $10 \mathrm{mV}, 1200 \mathrm{~ms}$; see Fig. 4). The TOC inactivation was assessed by conditioning steps (from -100 to -30 $\mathrm{mV}, 500 \mathrm{~ms}$ ), followed by a longer step ( $-10 \mathrm{mV}, 1200 \mathrm{~ms}$; Fig. 4).

In a voltage-clamp configuration we recorded the evoked EPSCs (eEPSCs) and the spontaneous postsynaptic currents ( gapfree mode).

Data analysis of patch-clamp experiments. All experiments were recorded using the software Clampex (pClamp v10, Axon Instruments) and were analyzed off-line using the software Clampfit (pClamp v10, Axon Instruments) or Mini Analysis Program (Synaptosoft). The data were expressed as mean \pm SEM using GraphPad Prism v4. Significance was established at $p<0.05$.

The junction potential between the external and electrode solutions was $\sim-14 \mathrm{mV}$ and resting membrane potentials (RMP) were corrected with this value. The $R_{\text {input }}$ was determined via linear regression applied to the linear portion of the voltage-current relationship after hyperpolarizing injected current. Membrane capacitance $\left(C_{\mathrm{m}}\right)$ was calculated by dividing the membrane time constant by $R_{\text {input }}$ and the membrane time constant was measured by fitting a single exponential function to the data points in the hyperpolarizing phase of the same recording. The RMP, $C_{\mathrm{m}}$ and $R_{\text {input, }}$ frequency, amplitude, half-width, rise time or decay time of the currents were compared using unpaired Student's $t$ test (GraphPad Prism v4).

The number of action potential induced by positive injected current or TS stimulation from control or SH rats were compared using two-way ANOVA with Tukey post hoc testing (GraphPad Prism v4). The delay excitation was considered as a delay in the occurrence of action potentials after depolarized step preceded by a hyperpolarized step (Dekin and Getting, 1987; Dekin et al., 1987; Moak and Kunze, 1993).

The $\mathrm{IK}_{\mathrm{A}}$ was isolated by digital subtraction of the steady-state current (SS) from TOC. TOC peak was measured 2-4 ms after capacitive transients in the long step and SS was measured near the end of the long step in each protocol (see Fig. 4).

Activation curve as well as inactivation curve for $\mathrm{IK}_{\mathrm{A}}$ was fit with the Boltzmann function using data analysis Prism software (GraphPad Prism v4), according to previous studies from our laboratory (Moraes et al., 2013).

The conductance $(G)$ of $\mathrm{IK}_{\mathrm{A}}$ was calculated as follows:

$$
G=I_{\text {peak }} /\left(V_{\mathrm{m}}-E_{\mathrm{K}}\right),
$$

where $I_{\text {peak }}$ is peak current, $V_{\mathrm{m}}$ is membrane voltage, and $E_{\mathrm{K}}$ is the potassium equilibrium potential calculated by Nernst equation, which in our experimental conditions was $98.6 \mathrm{mV}$.

The relationship between normalized conductance $\left(G / G_{\max }\right)$ and membrane potential were fitted by the Boltzmann function using data analysis Prism software v4 (GraphPad):

$$
\mathrm{G} / \mathrm{G}_{\max }=\frac{1}{1+\exp \cdot\left[\frac{\mathrm{V}_{1 / 2}-\mathrm{V}_{\mathrm{m}}}{\mathrm{V}_{\mathrm{c}}}\right]},
$$

where $V_{1 / 2}$ is the voltage at half-maximal conductance and $V c$ is the slope factor.

Voltage-dependent inactivation of the TOC was fitted with Boltzmann function using data analysis Prism software v4 (GraphPad):

$$
\mathrm{I} / \mathrm{I}_{\max }=\frac{1}{1+\exp \cdot\left[\frac{\mathrm{V}_{1 / 2}-\mathrm{V}_{\mathrm{m}}}{\mathrm{V}_{\mathrm{c}}}\right]},
$$

where $I_{\max }$ is the maximal current recorded.

The curves for $\mathrm{IK}_{\mathrm{A}}$ analyzes (activation, inactivation, conductance or 4-AP-sensitive current curves) were compared using two-way ANOVA with Tukey post hoc testing (GraphPad Prism v4).

Drugs. The brainstem slice in the recording chamber was perfused with aCSF by a gravity-driven perfusion system (flow: $2-3 \mathrm{ml} / \mathrm{min}^{-1}$ ). All drugs were diluted in the aCSF solution and the flow throughout the recording chamber containing the slices was regulated by a six-valve solenoid system (VC-6; Warner Instruments). Bicuculline free-base, a $\mathrm{GABA}_{\mathrm{A}}$ receptor antagonist, was dissolved in dimethylsulphoxide (DMSO; Sigma-Aldrich); the final concentration of DMSO in the aCSF bath was in the range of $0.1 \%$. 4-aminopyridine (4-AP; $\mathrm{IK}_{\mathrm{A}}$ blocker), fluoracetate (FAC), bicuculline, and DMSO were obtained from SigmaAldrich. Tetrodotoxin (TTX; sodium channel blocker) was obtained from Tocris Bioscience.

\section{Results}

\section{SH, baroreflex, and chemoreflex responses}

In in situ preparations under the same conditions of flow rate, temperature, and perfusate content, we verified that preparations from $\mathrm{SH}$ rats developed higher levels of perfusion pressure [PP; control: $63 \pm 1 \mathrm{mmHg}(n=18)$ vs SH: $78 \pm 1.8 \mathrm{mmHg}(n=17)$; $p<0.0001]$ than preparations from control rats, indicating an increased vascular resistance in $\mathrm{SH}$ rats as described previously (Moraes et al., 2014). We next evaluated the autonomic and respiratory reflexes sensitivity in in situ preparations from control and $\mathrm{SH}$ groups.

The changes in $\mathrm{tSN}, \mathrm{HR}, \mathrm{AbN}$, and $\mathrm{PN}$ activities were measured in response to stimulation of carotid chemoreceptors with intra-arterial injections of $\mathrm{KCN}$, which increased $\mathrm{tSN}$ in both control and $\mathrm{SH}$ rats (Fig. $1 A, B$ ). The increase in the $\mathrm{tSN}$ was significantly enhanced in $\mathrm{SH}$ rats during expiratory phase [control: $101.3 \pm 1.7 \%(n=9)$ vs SH: $126.5 \pm 4.4 \%(n=11) ; p<$ 0.001 ], but not during inspiratory [control: $16.1 \pm 1.4 \%(n=9)$ vs SH: $16.7 \pm 2.1 \%(n=11) ; p=0.82$; Fig. $1 A, B, C]$. Accordingly, in $\mathrm{SH}$ rats the $\mathrm{AbN}$ expiratory response was also more pronounced than in control rats [control: $381.3 \pm 4.1 \%(n=12)$ vs $\mathrm{SH}: 463.7 \pm 13.6 \%(n=10) ; p<0.0001$; Fig. $1 A, B, D]$, whereas the inspiratory [(frequency of PN) control: $0.36 \pm 0.02 \mathrm{~Hz}(n=$ 12) vs SH: $0.38 \pm 0.07 \mathrm{~Hz}(n=11) ; p=0.77]$ and bradycardic [control: $-193 \pm 6 \mathrm{bpm}(n=12)$ vs SH: $-207 \pm 9 \mathrm{bpm}(n=$ $11) ; p=0.2]$ responses were not different between the groups (Fig. $1 A, B)$.

Stimulation of aortic depressor nerve (ADN), containing mainly baroreceptor afferent fibers (Brophy et al., 1999), in the in situ preparation resulted in a well described sympatho-inhibition 
A

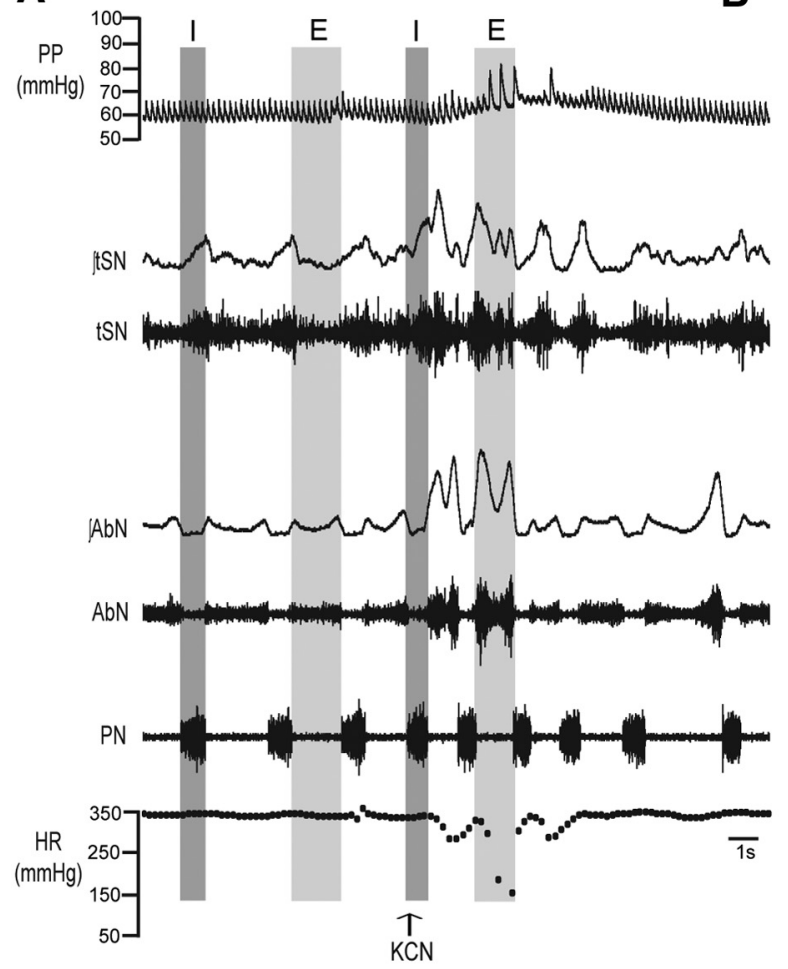

B

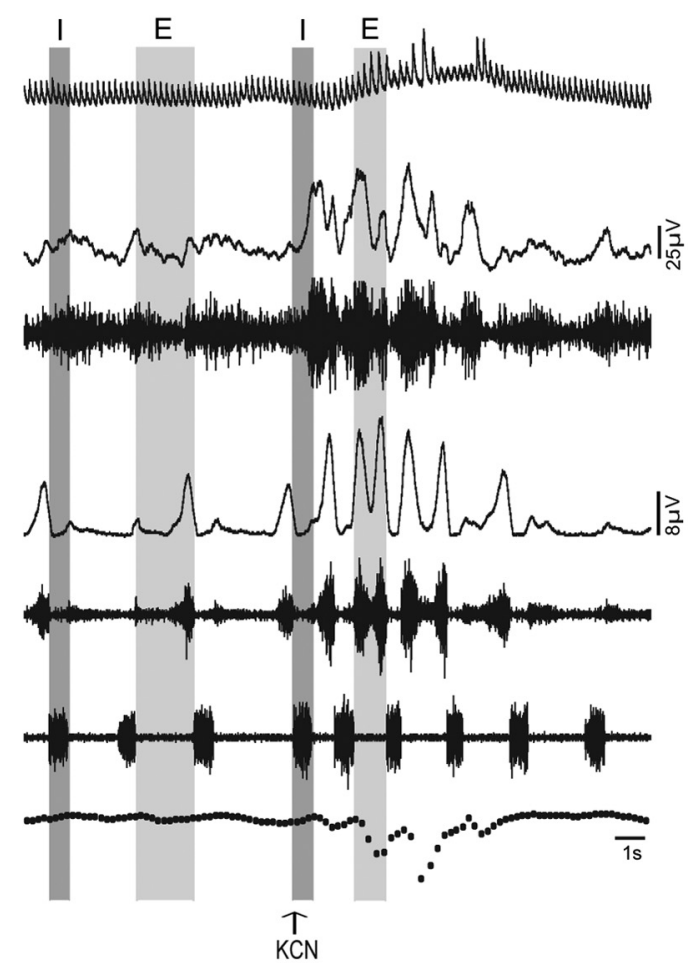

C

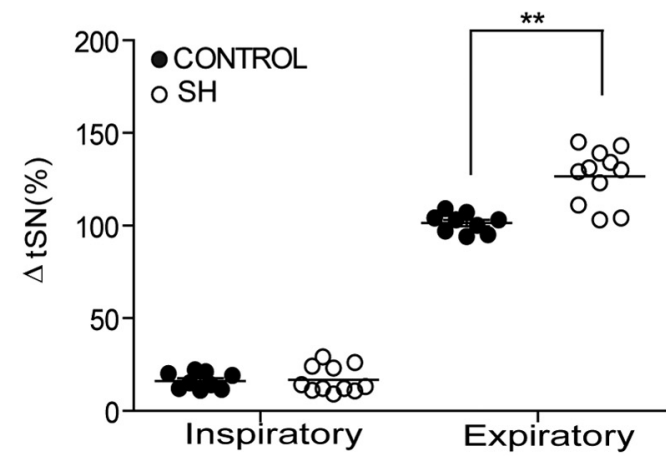

D

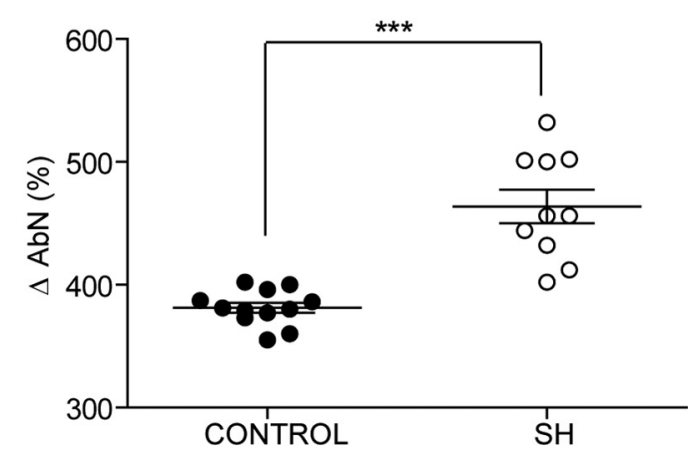

Figure 1. Peripheral chemoreflex responses in control and $S H$ rats. Raw and integrated $\left(\int\right)$ recordings of $A b N$, $t S N$, and PN activities, and $H R$ of a control $(\boldsymbol{A})$ and a $S H$ rat $(\boldsymbol{B})$, representatives of their respective groups, illustrating the respiratory, sympathetic, and bradycardic responses elicited by the activation of peripheral chemoreceptors with intra-arterial injection of KCN ( $0.05 \%, 50 \mu l)$. The percentage of average magnitude of the $\operatorname{SN}(\boldsymbol{C})$ and $\mathrm{AbN}(\boldsymbol{D})$ reflex responses to peripheral chemoreflex activation in control and SH rats. I, Inspiration; E, expiration; PP, perfusion pressure. ${ }^{* *} p<0.001$, ANOVA one-way; ${ }^{* * *} p<0.0001$, unpaired $t$ test.

and bradycardia, as well as a prolongation of the expiratory duration (Baekey et al., 2008). The magnitudes of the responses are dependent on the respiratory phase in which the stimulus is applied, with the maximal greatest effect occurring immediately after inspiration, i.e., postinspiration. Considering that a comprehensive study of the respiratory modulation of baroreflex function has been described in in situ preparations (Baekey et al., 2008), we evaluated the effects of SH on the sympatho-inhibitory and bradycardiac components of baroreflex within the postinspiratory phase of the respiratory cycle. SH rats presented higher sympatho-inhibitory [twofold the threshold: control: $64.2 \pm$ $2.2 \%(n=6)$ vs SH: $84.1 \pm 1.7 \%(n=6) ; p<0.0001$; Fig. $2 A, B, C$ ] and bradycardic [twofold the threshold: control: $-30 \pm$ $1.5 \mathrm{bpm}(n=6)$ vs SH: $-46.6 \pm 2.9 \mathrm{bpm}(n=6) ; p=0.0005$; Fig. $2 A, B, D]$ responses to baroreflex activation than control rats, but no changes in the prolongation of expiratory period [control: $6.1 \pm 1.2 \mathrm{~s}(n=6)$ vs SH: $5.7 \pm 0.4 \mathrm{~s}(n=6), p=0.75$; Fig. $2 A, B]$.
Consistent with the observation that the $\mathrm{tSN}$ and $\mathrm{HR}$ responses are more pronounced to baroreflex activation in $\mathrm{SH}$ rats, the intensity required to produce $50 \%$ of inhibition of tSN [control: $1.6 \pm 0.1$ the threshold $(n=6)$ vs SH: $1.0 \pm 0.07$ the threshold $(n=6) ; p=0.0006$ ] and HR [control: $1.9 \pm 0.22$ the threshold $(n=6)$ vs SH: $2.5 \pm 0.14$ the threshold $(n=6) ; p=0.04]$ was lower in $\mathrm{SH}$ rats than in control rats (fit using a logistic equation; see methods). Therefore, our results demonstrate that $\mathrm{SH}$ affects the processing of both baroreflexes and chemoreflexes.

\section{Electrophysiological properties of NTS neurons}

Considering the effects of $\mathrm{SH}$ on baroreflexes and chemoreflexes, we then evaluated whether $\mathrm{SH}$ also affected the synaptic transmission at the NTS level, because NTS neurons receive the afferent fibers from arterial baroreflexes and chemoreflexes (Contreras et al., 1982; Seiders and Stuesse, 1984; Claps and Torrealba, 1988; Barraco et al., 1992; Finley and Katz, 1992; Mendelowitz et al., 1992; Machado, 

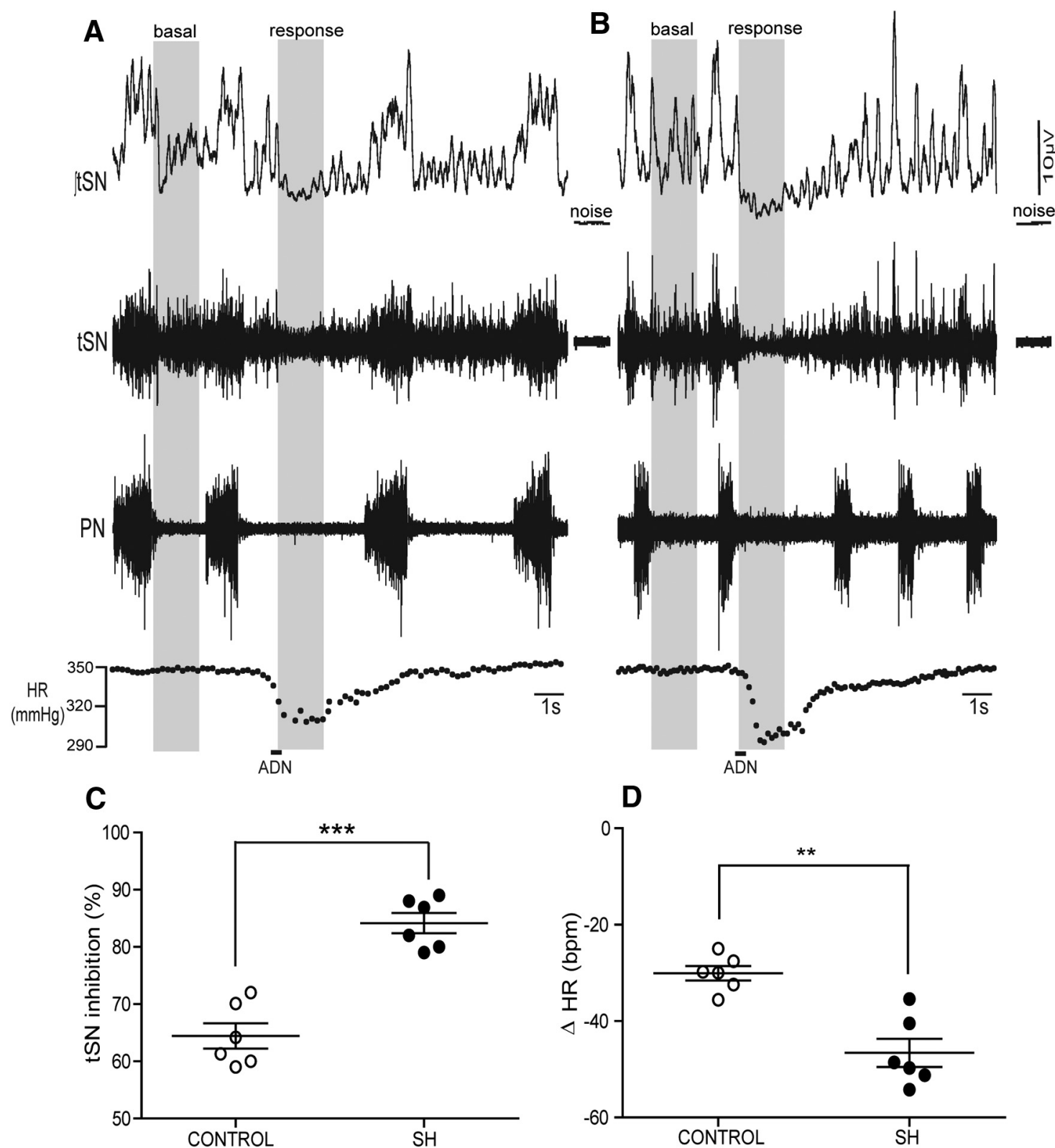

D

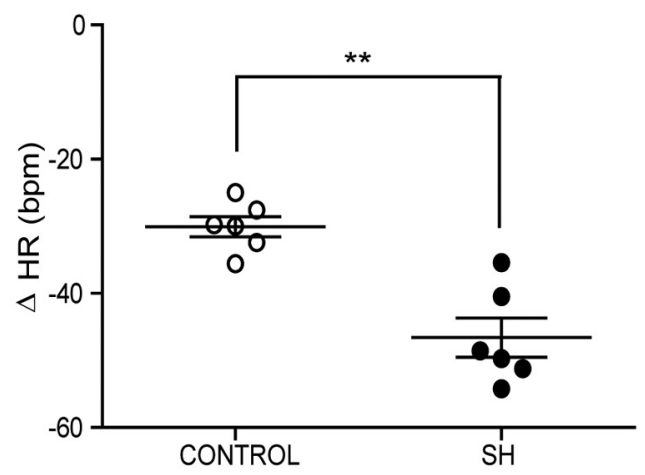

Figure 2. Sympatho-inhibitory component of baroreflex in control and SH rats. Raw and integrated $\left(\int\right)$ recordings of tSN and PN activities and HR of a control $(\boldsymbol{A})$ and a SH rat $(\boldsymbol{B})$, representatives of their respective groups, illustrating the sympatho-inhibitory, bradycardic, and expiratory responses elicited by the activation of baroreflex before (basal) and during ADN stimulation (response). The percentage of average magnitude of the tSN inhibition $(\boldsymbol{C})$ and HR (D) reflex responses to baroreflex activation in control and SH rats; ${ }^{* *} p<0.001,{ }^{* * *} p<0.0001$, unpaired $t$ test.

2001, 2004). Whole-cell patch-clamp recordings were obtained from 186 nonlabeled NTS neurons from 41 rats. The nonlabeled NTS neurons were located mainly in the commissural NTS level, as illustrated in Figure 3. In addition, we also performed wholecell patch-clamp experiments in 19 second order NTS-labeled neurons from 10 rats. The second-order NTS neurons receiving afferents inputs from baroreceptors and chemoreceptors were morphologically identified with DiI tracer (see Fig. 5).

\section{SH and passive properties of nonlabeled NTS neurons}

$\mathrm{SH}$ produced no changes in the resting membrane potential [control: $-68 \pm 2.7 \mathrm{mV}(n=31) \mathrm{vs} \mathrm{SH}:-66 \pm 2.4 \mathrm{mV}(n=21)$, $p=0.6283$ ], input resistance [control: $1.16 \pm 0.2 \mathrm{G} \Omega(n=21)$ vs SH: $1.14 \pm 0.11 \Omega(n=25), p=0.9366]$ or capacitance of nonlabeled NTS neurons [control: $72.8 \pm 8 \mathrm{pF}(n=14)$ vs SH: $52.4 \pm 7 \mathrm{pF}(n=20), p=0.0736]$.

\section{SH and active properties of nonlabeled NTS neurons}

In current-clamp configuration we measured the spike discharge frequency of NTS neurons after positive injected current $(0,12.5$, $25,37.5$, and $50 \mathrm{pA}$ ) into neurons from control and $\mathrm{SH}$ rats (Fig. $3 C)$. The NTS neurons from SH rats presented higher spike discharge frequency than control rats in response to all values of injected current (Fig. 3D). The reduced excitability of NTS neurons from control rats compared with NTS neurons form SH rats seems to be related to a larger afterhyperpolarization phase (AHP) of action potential. This is the hyperpolarizing phase of action potential (Storm, 1987), which may contribute to limit the cell firing in response to sustained depolarization (Madison and Nicoll, 1984; Lancaster and Nicoll, 1987). However, in the present study the amplitudes of AHP in NTS neurons in control and $\mathrm{SH}$ groups were similar [+37.5 pA injected current: control $-56.7 \pm 3(n=11)$ vs SH-54.6 $\pm 2.7(n=19), p=0.6204]$, 
A

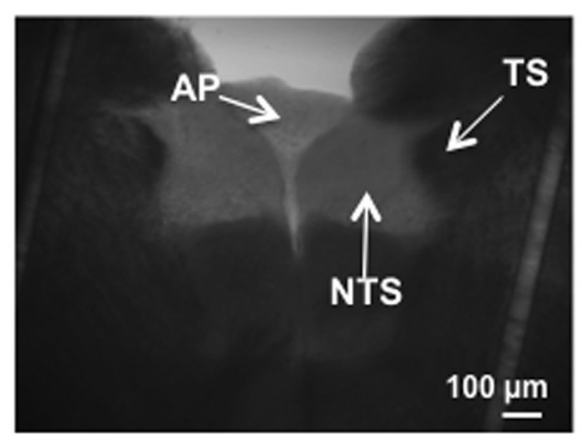

C

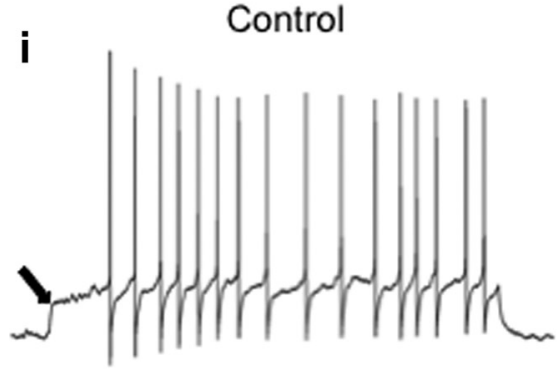

$50 \mathrm{pA}$

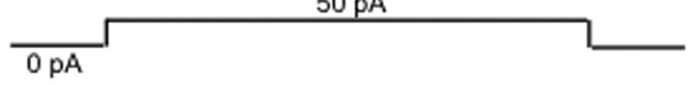

B

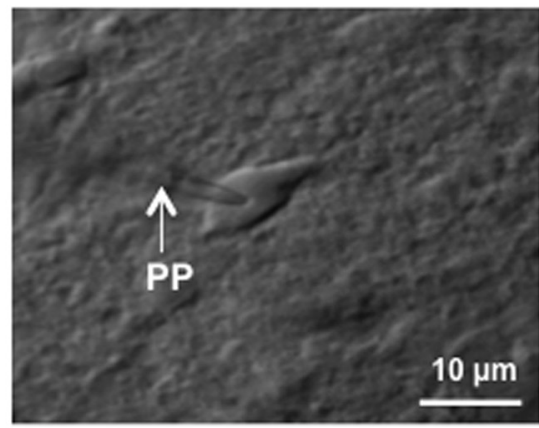

$\mathrm{SH}$

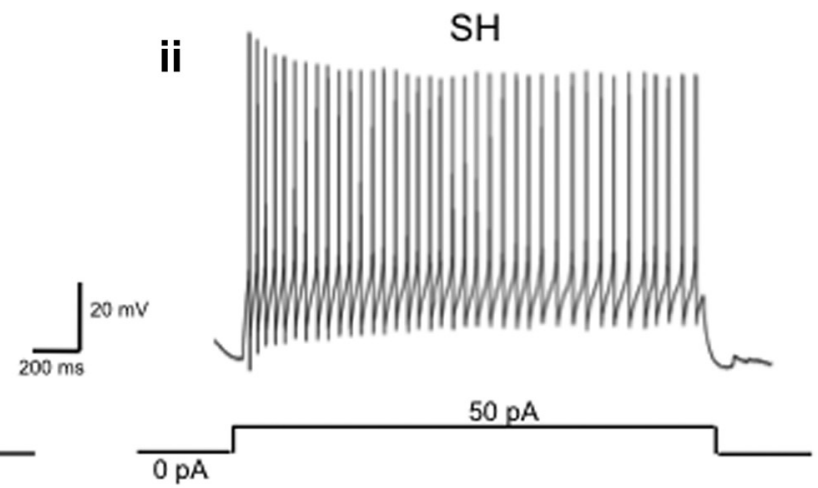

D

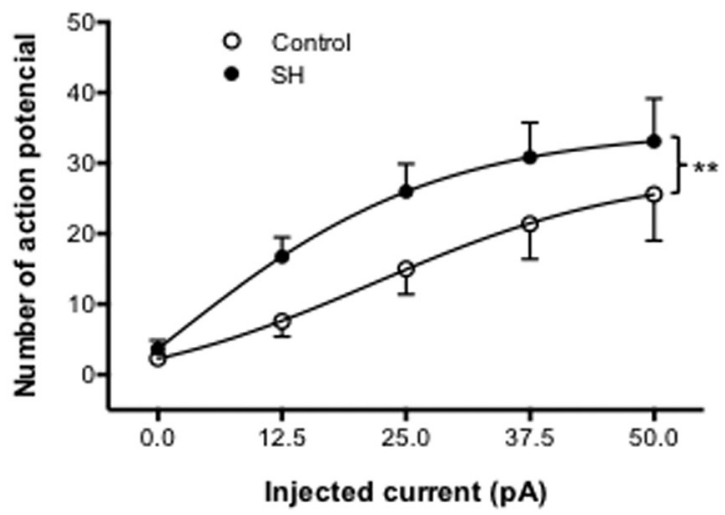

Figure 3. Nonlabeled NTS neurons of SH animals present increased firing frequency in response to injected current. $A$, Photomicrography showing brainstem slice at the NTS level viewed under IR-DIC. AP, Area postrema; TS, tractus solitarius; NTS, nucleus tractus solitarius. B, Photomicrography showing one NTS neuron and the patch pipette (PP) on the surface of slice viewed on IR-DIC optic. Ci, Representative trace showing the number of action potential after inject current (50 pA during 2 s) into NTS neuron from control rat; note the delay excitation (black arrow). Cii, Representative tracing showing the number of action potential after inject current ( $50 \mathrm{pA}$ during $2 \mathrm{~s}$ ) into NTS neuron from SH animals. $D$, Correlation between the injected current and the number of action potential in NTS neurons from control $(n=14)$ and SH animals $(n=19) ;{ }^{* *} p<0.01$, ANOVA two-way.

indicating that the changes in NTS neurons from the SH rats are not related to the AHP amplitude. Moreover, in neurons from control rats we observed a delayed excitation (Fig. 3C, arrow), which was defined as a delay in the occurrence of action potentials after depolarized step preceded by a hyperpolarized step (Dekin and Getting, 1987; Dekin et al., 1987; Moak and Kunze, 1993). The delayed excitation was longer in control than SH rats [at $+37.5 \mathrm{pA}$ of injected current: control $89.7 \pm 4.1 \mathrm{~ms}(n=11)$ vs SH $14.55 \pm 2.8 \mathrm{~ms}(n=17) ; p=0.0310]$.

\section{SH and TOC in nonlabeled and labeled NTS neurons}

Considering that the delayed excitation in NTS neurons is a consequence of TOC activation (Dekin and Getting, 1987; Dekin et al., 1987; Moak and Kunze, 1993; Paton et al., 1993; Tell and Bradley, 1994; Sundaram et al., 1997; Uteshev and Smith, 2006; Suwabe and Bradley, 2009), herein we evaluated the possibility that $\mathrm{SH}$ reduces the TOC and affects the delayed excitation.

These experiments were performed in the presence of TTX in aCSF solution to block the voltage-dependent sodium currents. Depolarization voltage steps (from -100 to $10 \mathrm{mv}$ ) from a conditioning potential of $-90 \mathrm{mV}$ elicited large voltage-dependent TOC that decayed over time in nonlabeled NTS neurons from control and $\mathrm{SH}$ rats (Fig. 4A). However, the amplitude of TOC was significantly different between nonlabeled NTS neurons from control and SH rats [control: $1428 \pm 600 \mathrm{pA}, V_{\mathrm{m}}=10 \mathrm{mV}$ $(n=10)$ vs SH: $334 \pm 76 \mathrm{pA} V_{\mathrm{m}}=10 \mathrm{mV}(n=10)$; Fig. $\left.4 B\right]$. 
Moreover, activated TOC presented similar voltage-dependent activation kinetics in nonlabeled NTS neurons from control $\left[V_{1 / 2}\right.$ $=-25.3 \pm 1.1 \mathrm{mV} ; V_{\mathrm{c}}=7.2 \pm 1.1(n=10)$; Fig. $\left.4 \mathrm{C}\right]$ or SH rats $\left[V_{1 / 2}=-31 \pm 2.2 \mathrm{mV} ; V \mathrm{c}=7.4 \pm 2(n=9)\right.$; Fig. $\left.4 C\right]$. The reduction in TOC amplitude after $\mathrm{SH}$ was also observed on morphologically identified NTS neurons receiving afferent inputs from the ADN or CB fibers (second-order NTS neurons; Fig. 5). There was no difference between SS currents of NTS neurons from control or SH rats $(+10 \mathrm{mV}$ : control $789 \pm 190 \mathrm{pA}$ vs $\mathrm{SH}$ $923 \pm 180 \mathrm{pA}, p=0.6346)$.

The voltage-dependent inactivation was different between nonlabeled NTS neurons from control and SH rats (Fig. 4E,F). In nonlabeled NTS neurons from control group the peak inactivation current was higher $\left(795 \pm 183 \mathrm{pA}, V_{\mathrm{m}}=-100 \mathrm{mV} ; n=\right.$ 12) compared with those from $\mathrm{SH}$ rats $\left(342 \pm 73 \mathrm{pA}, V_{\mathrm{m}}=-100\right.$ $\mathrm{mV} ; n=11)$. However, the kinetic of TOC inactivation of both groups was similar [control rats: $V_{1 / 2}=-74 \pm 2 \mathrm{mV} ; \mathrm{Vc}=-8 \pm$ $2(n=12)$; SH rats: $V_{1 / 2}=-74 \pm 4 \mathrm{mV} ; V_{\mathrm{c}}=-11 \pm 4(n=11)$; Figure $4 G]$.

\section{Pharmacological characterization of TOC in nonlabeled NTS neurons}

In our experiments TOC were consistent with the activation of an early, transient outward current, named $\mathrm{IK}_{\mathrm{A}}$, which turns on with depolarization but subsequently it is inactivated (Pongs, 1999). To identify the currents, we tested whether the TOC were sensitive to 4-AP (5 mM), a blocker of $\mathrm{IK}_{\mathrm{A}}$ (Mathie et al., 1998). TOC was reduced by 4 -AP (Fig. $4 D, H$ ), suggesting that the TOC recorded in nonlabeled NTS neurons resemble $\mathrm{IK}_{\mathrm{A}}$.

\section{Glial inhibition and $\mathrm{IK}_{\mathrm{A}}$ in nonlabeled NTS neurons}

Recent study by Naskar and Stern (2014) demonstrated that the astrocytic inhibition induces a reduction of $\mathrm{IK}_{\mathrm{A}}$ amplitude in hypothalamic magnocellular neurosecretory neurons, involving extrasynaptic NMDA receptor activation and $\mathrm{Ca}^{2+}$-dependent, protein kinase $\mathrm{C}$-dependent pathways. To determine whether or not astrocytic inhibition also decrease $\mathrm{IK}_{\mathrm{A}}$ in nonlabeled NTS neurons, we performed experiments with FAC, a glial metabolism inhibitor (Fonnum et al., 1997). We incubated the slices with FAC $(1 \mathrm{mM})$ during $1 \mathrm{~h}$ before the experiments and $\mathrm{IK}_{\mathrm{A}}$ in nonlabeled NTS neurons was registered in the presence of TTX + FAC. The glial inhibition decreased the $\mathrm{IK}_{\mathrm{A}}$ in control rats [aCSF: $1227 \pm 129 \mathrm{pA}, V_{\mathrm{m}}=10 \mathrm{mV}(n=7)$ vs aCSF + FAC: $605 \pm 210$ pA $V_{\mathrm{m}}=10 \mathrm{mV}(n=7), p=0.0246$; Fig. $\left.6 \mathrm{~A}\right]$, but produced no change in the current amplitude of SH rats [aCSF: $475 \pm 110 \mathrm{pA}$, $V_{\mathrm{m}}=10 \mathrm{mV}(n=4)$ vs aCSF + FAC: $427 \pm 114 \mathrm{pA}, V_{\mathrm{m}}=10 \mathrm{mV}$ $(n=6)$; Fig. $6 B]$.

\section{SH and afferent fibers stimulation}

Considering that $\mathrm{SH}$ changed the intrinsic electrophysiological properties of NTS neurons, afterward we evaluated the possibility that $\mathrm{SH}$ also affects the synaptic transmission at the NTS level. These experiments were performed in the presence of bicuculline $(20 \mu \mathrm{M})$ in aCSF solution, to isolate the excitatory transmission. At steady resting potentials, five ST stimuli evoked action potential in nonlabeled NTS neurons from control and SH rats (Fig. $7 A$ ). Nonlabeled NTS neurons from SH rats presented a higher frequency discharge after TS stimulation compared with control rats $(p<0.0001 ;$ Fig. $7 B)$. Considering that increased numbers of action potential after TS stimulation could be related to: (1) a reduction of $\mathrm{IK}_{\mathrm{A}}$ and (2) also to an increase in the excitatory transmission, we measured the EPSCs evoked by TS-stimulation to evaluate the possible contribution of synaptic transmission.
TS-eEPSCs of nonlabeled NTS neurons from SH rats presented higher amplitude compared with those from control rats [control: $204.3 \pm 26 \mathrm{pA}(n=28)$ vs SH: $340 \pm 58 \mathrm{pA}(n=23)$; Fig. $7 C, D]$, but no changes were observed in the kinetic parameters, such as half-width (control: $7.11 \pm 0.41 \mathrm{~ms}$ vs SH: $6.8 \pm 0.40$ $\mathrm{ms}$; Fig. $7 E$ ), rise time (control: $3.04 \pm 0.3 \mathrm{~ms}$ vs $\mathrm{SH}: 2.3 \pm 0.3 \mathrm{~ms}$; Fig. $7 F$ ), or decay time of events (control: $13.4 \pm 0.85 \mathrm{~ms}$ vs SH: $13 \pm 0.89 \mathrm{~ms}$; Fig. $7 G$ ).

To evaluate whether or not the mechanism by which $\mathrm{SH}$ exerts its effect on evoked synaptic transmission involves an increase in presynaptic glutamate release and/or changes in the postsynaptic neuron, we used two approaches to study the synaptic plasticity: (1) comparison of the inverse of squared coefficient of variation $\left(1 / C V^{2}\right)$ of TS-eEPSCs amplitude (Bekkers and Stevens, 1990; Malinow and Tsien, 1990) and (2) frequency-dependent depression protocol (Miles, 1986; Glaum and Miller, 1995; Schild et al., 1995; Scheuer et al., 1996; Chen et al., 1999; Doyle and Andresen, 2001).

The analysis of $1 / C V^{2}$ is a measurement of presynaptic changes in transmitter release (Malinow and Tsien, 1990). Our data show that $1 / \mathrm{CV}^{2}$ was similar in $\mathrm{SH}$ and control rats [control: $71 \pm 19(n=26)$ vs SH: $87 \pm 20(n=23), p=0.5749]$, suggesting that the effect of SH on NTS neurons is not due to a presynaptic mechanisms. To test this possibility, we used a second approach to analyze the synaptic plasticity and to reach this goal we applied a train of five TS stimuli at $33 \mathrm{~Hz}$, which produces a depression in the amplitude of evoked event. This depression in current amplitude is considered to be primarily mediated by presynaptic mechanisms and related to neurotransmitter release probability (Zucker and Regehr, 2002). We compared the amount of shortterm synaptic depression of TS-eEPSCs in nonlabeled NTS neurons, from both control and $\mathrm{SH}$ rats. We observed that the magnitude of depression was similar in both groups [second, third, fourth, and fifth normalized TS-eEPSCs; control: $47 \pm 3.8$, $34 \pm 3.3,32 \pm 4$, and $39 \pm 34.4 \%$; $(n=24)$ vs SH: $51 \pm 35.2,39 \pm$ $5.1,31 \pm 5.4$, and $33 \pm 7 \%,(n=17)$; two-way ANOVA, $p=$ 0.3699 ], indicating that $\mathrm{SH}$ produces no effect on release probability. Therefore, this analysis of synaptic plasticity confirmed that $\mathrm{SH}$ is not affecting presynaptic mechanism of nonlabeled NTS synaptic transmission.

\section{SH and spontaneous synaptic transmission of NTS neurons}

The effect of SH on spontaneous postsynaptic currents (sPSCs) was also evaluated. We measured the sPSCs in nonlabeled NTS neurons (Fig. 8A), which include excitatory and inhibitory currents (Accorsi-Mendonça et al., 2007). sPSCs of nonlabeled NTS neurons from $\mathrm{SH}$ rats presented a higher frequency compared with those from control rats [control: $3.4 \pm 0.44 \mathrm{~Hz}(n=19)$ vs SH: $7.1 \pm 1.6 \mathrm{~Hz}(n=15), p=0.0213$; Fig. $8 B$ ], with no change in amplitude (control: $20 \pm 1.6 \mathrm{pA}$ vs SH: $22 \pm 2.8 \mathrm{pA}$; Fig. $8 B$ ) or half-width of events (control: $3.1 \pm 0.13 \mathrm{~ms}$ vs SH: $3.2 \pm 0.16 \mathrm{~ms}$; Fig. 8B).

To verify whether the effect of SH on sPSCs was due to excitatory or inhibitory currents, we isolated pharmacologically the excitatory transmission with bicuculline, a $\mathrm{GABA}_{\mathrm{A}}$ receptor antagonist, and the spontaneous EPSCs (sEPSCs; Fig. $8 C$ ) were recorded. sEPSCs of nonlabeled NTS neurons from SH rats presented a higher frequency compared with those from control rats [control: $2.7 \pm 0.3 \mathrm{~Hz}(n=22)$ vs SH: $4.54 \pm 0.8 \mathrm{~Hz}(n=28)$, $p=0.0331$; Fig. $8 D$ ], with no change in amplitude (control: $19 \pm$ $1.6 \mathrm{pA}$ vs SH: $23 \pm 2 \mathrm{pA}$; Fig. $8 D$ ) or half-width of events (control: $3.5 \pm 0.2 \mathrm{~ms}$ vs SH: $2.9 \pm 0.2 \mathrm{~ms}$; Fig. $8 D$ ). 
A i

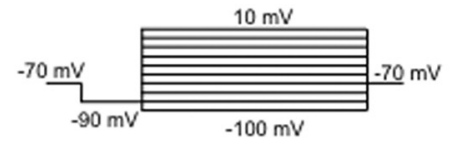

ii

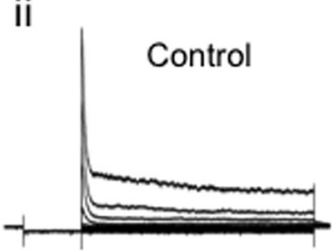

iii

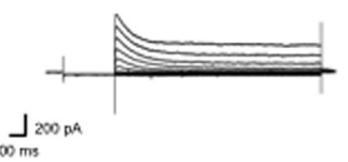

B

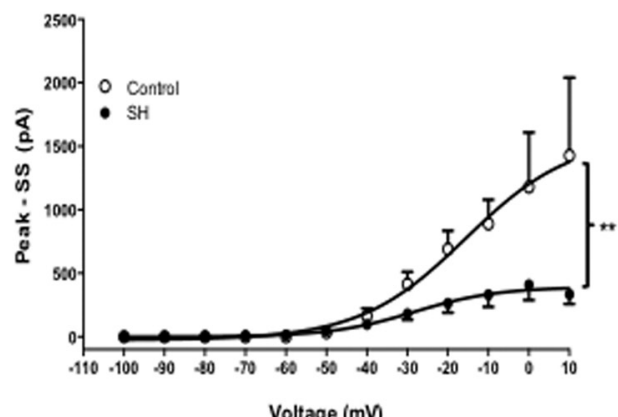

C

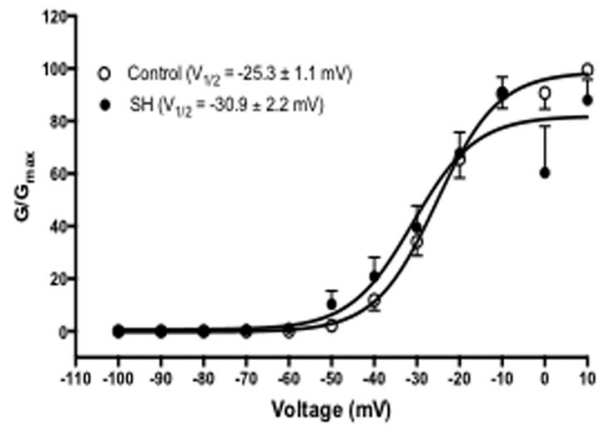

D

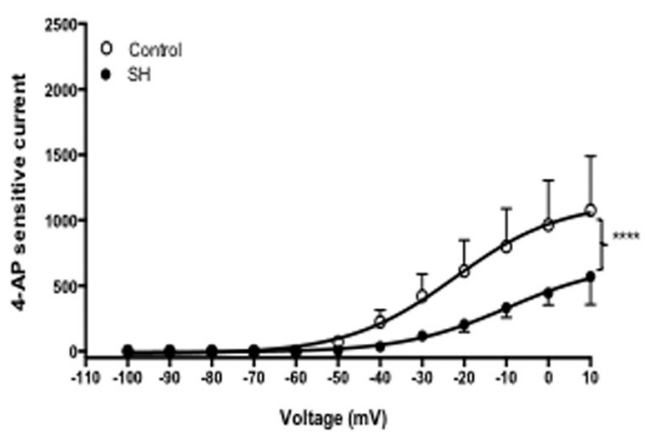

E

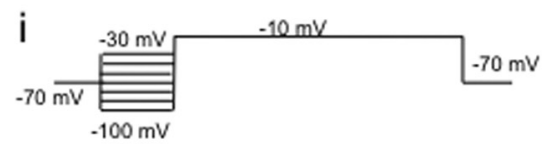

ii

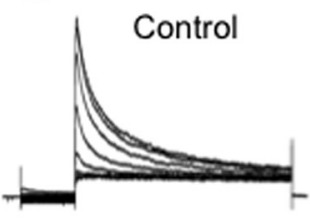

iii

$F$

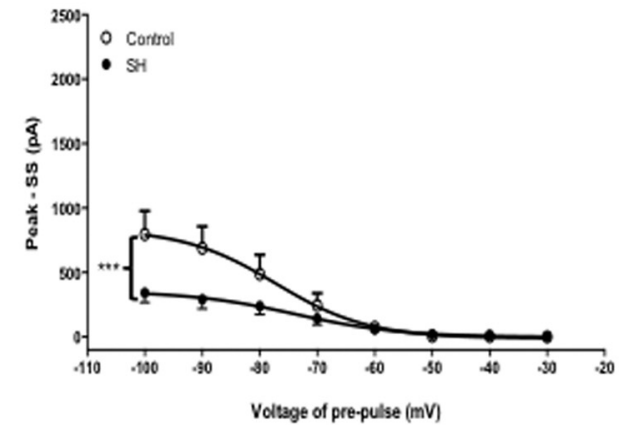

G

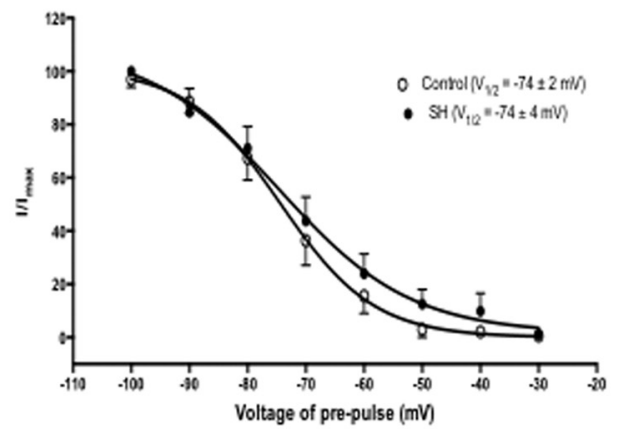

H

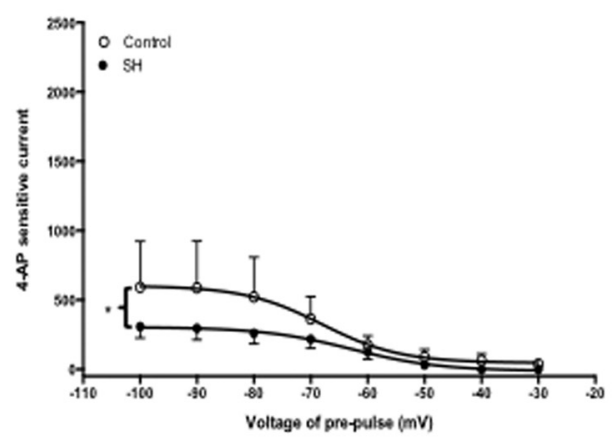

Figure 4. IK $\mathrm{K}_{\mathrm{A}}$ is decreased in nonlabeled NTS neurons from SH rats. Ai, Voltage-step protocols to activate outward currents in NTS neurons. The neurons were held at $-90 \mathrm{mV}$ for $500 \mathrm{~ms}$ followed by potentials step commands ( -100 to $10 \mathrm{mV}$ in $10 \mathrm{mV}$ increments during $1 \mathrm{~s}$ ). Aii, Representative traces showing the voltage-dependent activation of IK $\mathrm{A}_{\mathrm{A}}$ in NTS neuron from control animal. Aiii, Representative traces showing the voltage-dependent activation of $\mathrm{IK}_{A}$ in NTS neuron from SH animal. $\boldsymbol{B}$, The relationship between the IK $\mathrm{K}_{A}$ peak and voltage in NTS neurons from control $(n=9)$ and SH animals $(n=7) ;{ }^{* *} p<0.01$ ANOVA two-way. C, Correlation between the normalized conductance and voltage in NTS neurons from control $(n=9)$ and $S H$ animals $(n=7)$. $\boldsymbol{D}$, Correlation between the 4-AP-sensitive current and the voltage in NTS neurons from control $(n=6)$ and SH animals $(n=9)$. Ei, Voltage-step protocols to inactivate TOC in NTS neurons. Prepulses varied in 10 $\mathrm{mV}$ increments from -100 to $-30 \mathrm{mV}$ during $500 \mathrm{~ms}$, followed by a prolonged step ( $-10 \mathrm{mV}$ during $1200 \mathrm{~ms}$ ). Eii, Representative traces showing the voltage-dependent inactivation of $\mathrm{K}_{A}$ in NTS neuron from control animal. Eiii, Representative traces showing the voltage-dependent inactivation of TOC in NTS neuron from SH animal. $F$, Correlation between the $I K_{A}$ peak and the voltage of prepulse in NTS neurons from control $(n=9)$ and SH animals $(n=6)$. G, Correlation between the normalized conductance and the voltage of prepulse in NTS neurons from control $(n=9)$ and SH animals $(n=7)$. $\boldsymbol{H}$, Correlation between the 4-AP-sensitive current and the voltage of prepulse in NTS neurons from control $(n=5)$ and SH animals $(n=6) ;{ }^{*} p<0.05$, ${ }^{* *} p<0.01$; ${ }^{* * *} p<0.001$, ANOVA two-way. 

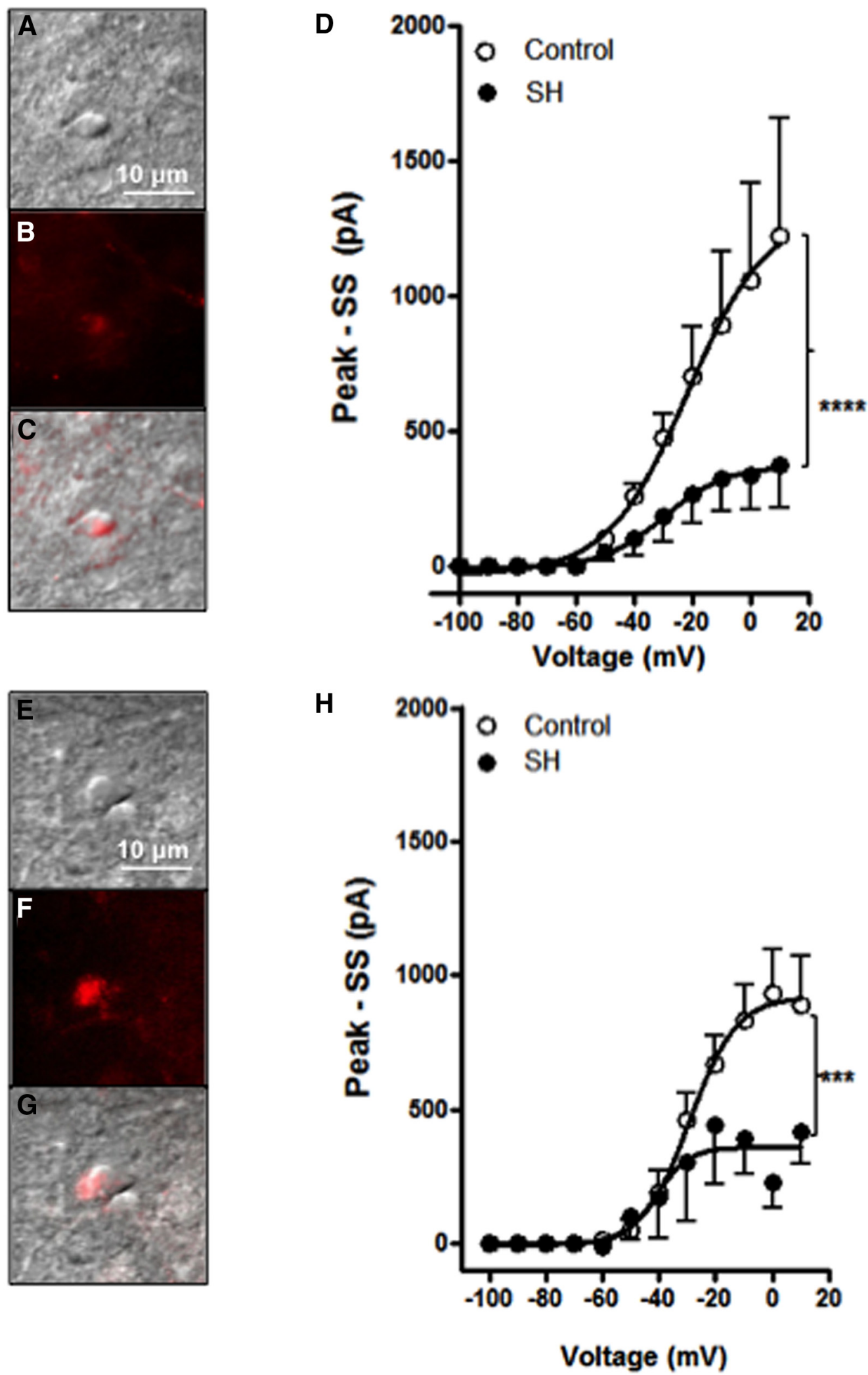

Figure 5. IK $\mathrm{K}_{\mathrm{A}}$ is decreased in second-order NTS neurons from SH rats. $A$, Photomicrography of NTS neuron that receive synaptic contacts from ADN showing the fluorescent afferent boutons viewed under IR-DIC optic. $\boldsymbol{B}$, The same neuron under epifluorescence illumination. C, Overlay of fluorescent and IR-DIC image. Fluorescent ADN terminals (red color) identify baroreceptor second-order NTS neuron in slices. $\boldsymbol{D}$, Correlation between the TOC peak and voltage in ADN-NTS neurons from control $(n=7)$ and SH animals $(n=7)$. $\boldsymbol{E}$, Photomicrography of the NTS neuron that receives synaptic contacts from CB showing the fluorescent afferent boutons viewed with IR-DIC optic. $\boldsymbol{F}$, The same neuron under epifluorescence illumination. $\boldsymbol{G}, 0$ verlay of fluorescent and IR-DIC image. Fluorescent CB terminals (red color) identify chemoreceptor second-order NTS neuron in a slice. $\boldsymbol{H}$, Correlation between the TOC peak and voltage in (B-NTS neurons from control $(n=4)$ and SH animals $(n=6) ;{ }^{* * *} p<0.001,{ }^{* * * *} p<0.0001$, ANOVA two-way. 

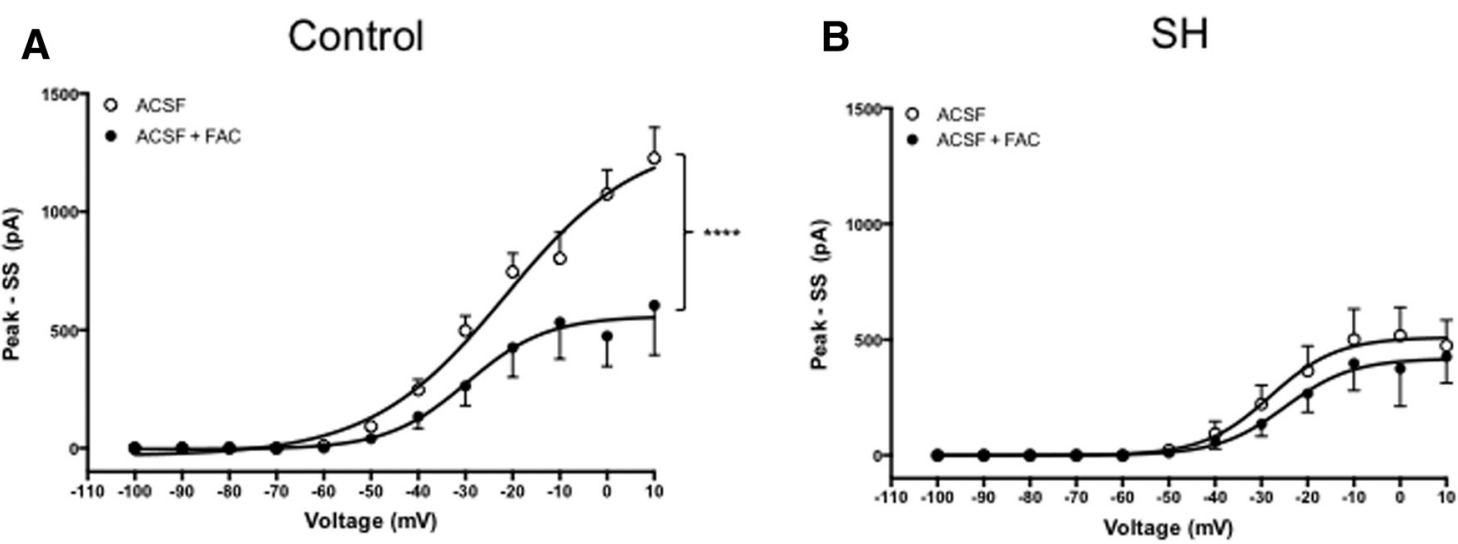

Figure 6. Glial inhibition and IK $\mathrm{K}_{A}$ in nonlabeled NTS neurons. $A$, Correlation between the TOC amplitude and voltage in NTS neurons from control rats during perfusion with aCSF $(n=7)$ or aCSF $+\mathrm{FAC}(n=7) \cdot \boldsymbol{B}$, Correlation between the IK amplitude and voltage in NTS neurons from SH rats during perfusion with aCSF $(n=4)$ or aCSF + FAC $(n=6)$; ${ }^{* * * *} p<0.0001$, ANOVA two-way.

Considering that $\mathrm{SH}$ affected the frequency but not the amplitude of sEPSCs, we assumed that $\mathrm{SH}$ is essentially affecting presynaptic mechanisms. To test this hypothesis, we evaluated the effect of $\mathrm{SH}$ on the action potential-independent events, i.e., the miniature excitatory transmission. For this purpose, we isolated pharmacologically the miniature sEPSCs (msEPSCs; Fig. $8 E$ ) using bicuculline and TTX. msEPSCs of nonlabeled NTS neurons from $\mathrm{SH}$ rats presented a similar frequency compared with those from control rats [control: $1.2 \pm 0.3 \mathrm{~Hz}(n=7)$ vs SH: $1.74 \pm 0.4 \mathrm{~Hz}(n=14)$; Fig. $8 F]$, with no change in amplitude (control: $15.2 \pm 3$ pA vs SH: $22 \pm 3$ pA; Fig. $8 F$ ) or half-width of events (control: $2.8 \pm 0.4 \mathrm{~ms}$ vs $\mathrm{SH}: 2.6 \pm 0.35 \mathrm{~ms}$; Fig. $8 F$ ). These data show that $\mathrm{SH}$ produced no effect on a postsynaptic mechanism (mean amplitude of mEPSCs; Neher and Sakaba, 2001), confirming the hypothesis that the effects of $\mathrm{SH}$ are essentially due to changes in the presynaptic terminal.

\section{Discussion}

In the present study, we verified that short-term $\mathrm{SH}\left(24 \mathrm{~h}, \mathrm{FI} \mathrm{O}_{2}\right.$ : $10 \%$ ) enhanced the sympathetic, bradycardic, and respiratory responses to baroreflex and chemoreflex activation, and produced important changes at NTS synaptic transmission. There is evidence that SH contributes to development of high blood pressure (Calbet, 2003; Tamisier et al., 2005). In a recent study, we showed that $\mathrm{SH}$ produced sympathetic overactivity and hypertension in rats (Moraes et al., 2014), which can be induced by increased peripheral chemosensitivity or carotid body tonicity as described in other hypertensive models, such as spontaneously hypertensive rats and heart failure (Abdala et al., 2012; McBryde et al., 2013; Ortega-Sáenz et al., 2013; Paton et al., 2013; Marcus et al., 2014). In the present study, we observed that $\mathrm{SH}$ produced an increase in expiratory response, but not inspiratory, and in expiratory-related sympatho-excitation to peripheral chemoreflex activation. We suggest that the enhanced expiratory response contributes to augmented sympathetic activity in $\mathrm{SH}$ rats as a consequence of a strengthened central coupling between the expiratory neurons of central pattern generator and medullary presympathetic neurons (Moraes et al., 2014). These findings suggest a critical role for altered central respiratory-sympathetic coupling in the development of hypertension after SH. Considering the increased mean arterial pressure (Moraes et al., 2014) and chemosensitivity (present study) after $\mathrm{SH}$, it was expected to find a reduction in the baroreflex sensitivity, as described in spontaneous hypertension (Head and Adams, 1988); however, our data show that $\mathrm{SH}$ produced an enhancement baroreflex sen- sitivity because the sympatho-inhibition and bradycardia to ADN stimulation was greater in SH rats. Therefore, the increase in baroreflex sympatho-inhibition and bradycardia in $\mathrm{SH}$ rats may be an important protective mechanism to bring back to normal levels the acute increase in arterial pressure mediated by changes in the expiratory modulation of presympathetic neurons in the rostral ventrolateral medulla (Moraes et al., 2014), as previously documented in rats submitted to $\mathrm{CIH}$ during $10 \mathrm{~d}$ (Zoccal et al., 2009). This new concept is in agreement with our recent data showing that $24 \mathrm{~h}$ after the cessation of exposure to $\mathrm{SH}$, the mean arterial pressure of $\mathrm{SH}$ rats returned to levels similar to those observed in control rats (Moraes et al., 2014), suggesting that the enhanced baroreflex function may play a key role in a fast normalization of the arterial pressure and also to prevent a greater increase in arterial pressure during $\mathrm{SH}$.

Considering that $\mathrm{SH}$ affected the processing of cardiovascular and respiratory reflexes and NTS is the first synaptic and integration site for the afferents of baroreflexes and chemoreflexes in $\mathrm{CNS}$, we hypothesized that after $\mathrm{SH}$ the changes in baroreceptor and chemoreceptor sensitivity are due to altered NTS neuronal activity. Therefore, we analyzed the $\mathrm{SH}$ effects on intrinsic properties and synaptic transmission of NTS neurons. We verified that SH has no effect on passive properties of NTS neurons, similarly to results using long-term SH protocol (Zhang et al., 2008, 2009).

The membrane excitability of NTS neurons was analyzed after injected positive current into these cells. SH increased firing after positive injected current and reduced the delay excitation, a well characterized delay between the onset and the first spike (Dekin et al., 1987). The presence of delayed excitation in NTS neurons from control rats is an indicative of $\mathrm{IK}_{\mathrm{A}}$, a outward current with fast activation at subthreshold voltages followed by fast inactivation (Cai et al., 2007). Because the delayed excitation was reduced in neurons from SH rats, we suggested that $\mathrm{SH}$ decreases the $\mathrm{IK}_{\mathrm{A}}$ in NTS neurons and this hypothesis was tested using electrophysiological and pharmacological protocols. We evaluated the $\mathrm{IK}_{\mathrm{A}}$ in nonlabeled NTS neurons as well on morphologically identified NTS neurons that receive afferent inputs from the ADN or $\mathrm{CB}$ fibers (labeled second-order neurons). The voltage-dependent characteristics and 4-AP sensitivity of these currents confirmed the hypothesis that the delayed excitation was mediated by $\mathrm{IK}_{\mathrm{A}}$ in nonlabeled NTS neurons. This result was also observed in second-order NTS neurons related to baroreceptors and chemo- 
A

Control

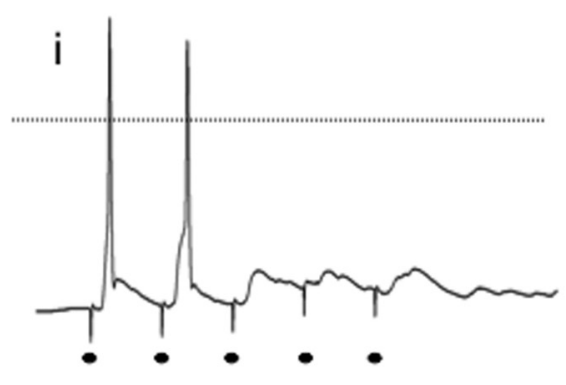

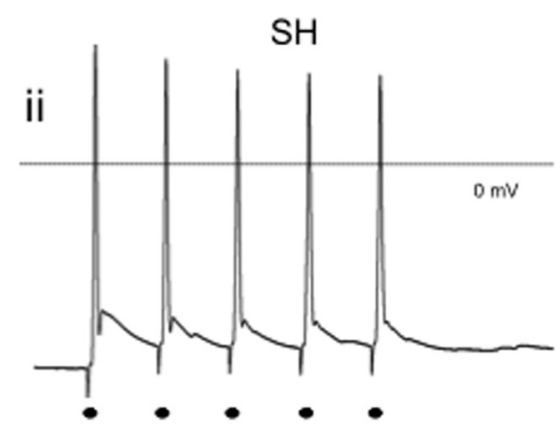

B

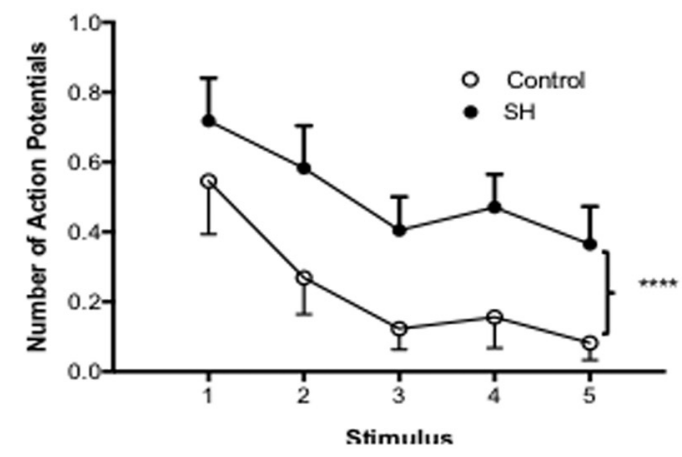

C

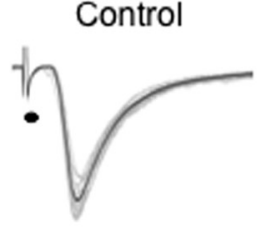

$E$

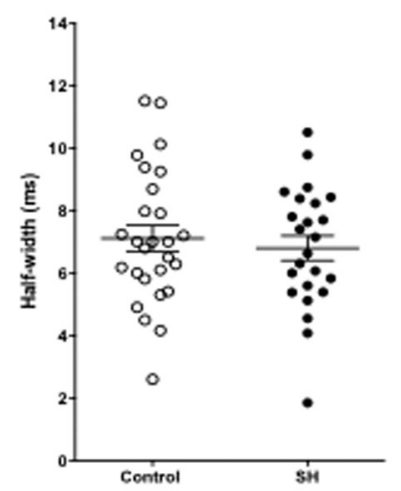

$\mathrm{SH}$

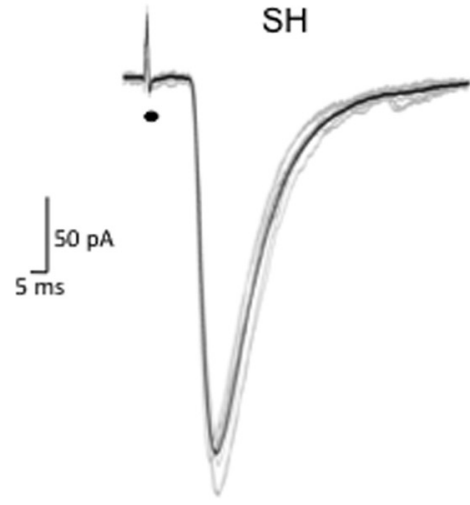

$\mathbf{F}$

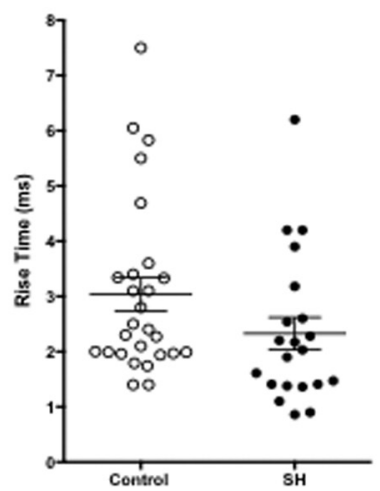

D

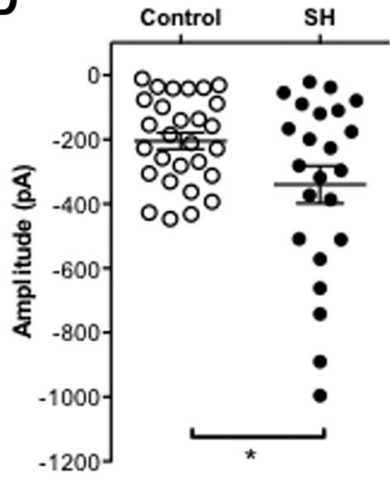

G

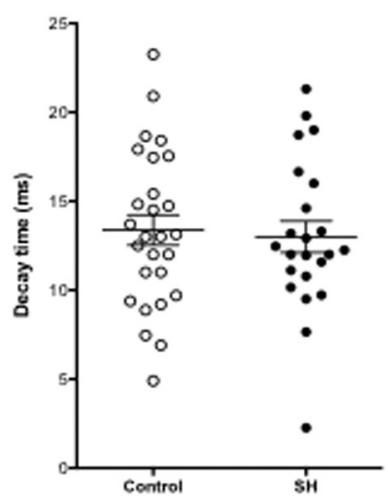

Figure 7. Evoked synaptic activity is increased in nonlabeled NTS neurons from SH rats. Ai, Representative trace of action potentials after 5 TS stimuli (black circle) in NTS neuron from control animal. Aii, Representative trace of action potential after five TS stimuli (black circle) in NTS neuron from SH animal. B, Correlation between number of action potential and TS stimuli. $\boldsymbol{C}$, Representatives traces of eEPSCs after TS stimulus (black circles) in NTS neuron from control and SH rat. $\boldsymbol{D}$, Average data of peak amplitude of TS-eEPSCs in NTS neurons from control and SH rat. $\boldsymbol{E}$, Average data of half-width of TS-eEPSCS in NTS neurons from control and SH animal. $\boldsymbol{F}$, Average data of rise time of TS-eEPSCS in NTS neurons from control and SH animal. $\boldsymbol{G}$, Average data of decay time of TS-eEPSCS in NTS neurons from control and SH animal; ${ }^{*} p<0.05$, unpaired $t$ test; ${ }^{* * * *} p<0.0001$, ANOVA two-way. 
A

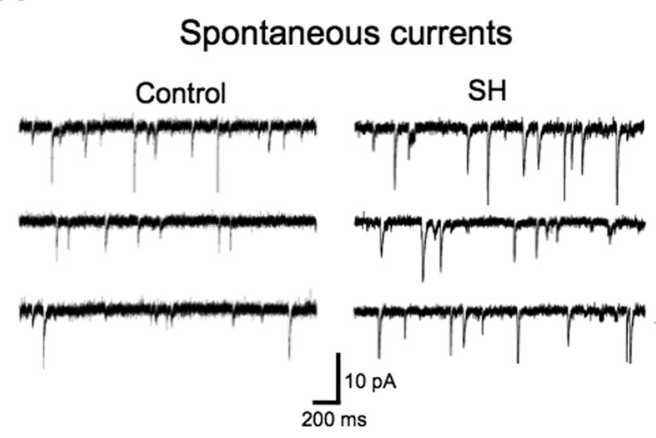

C

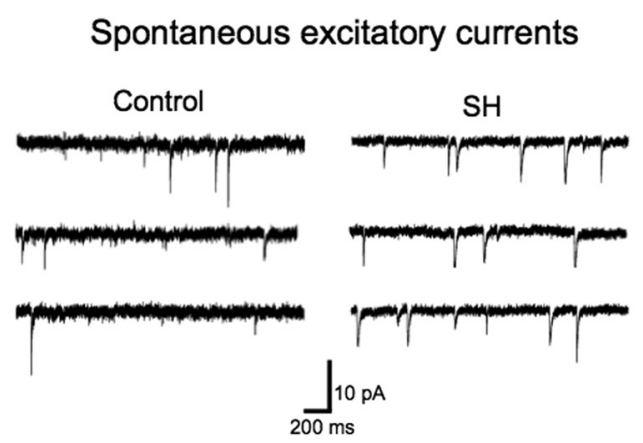

E

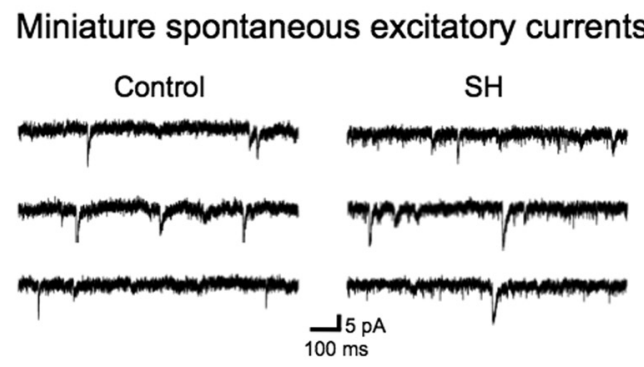

B

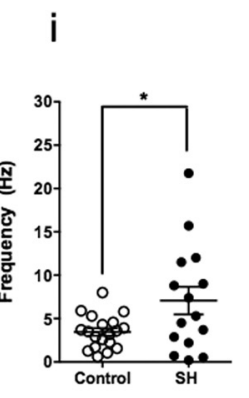

ii

iii
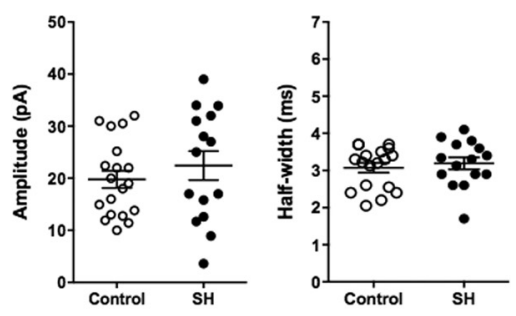

D
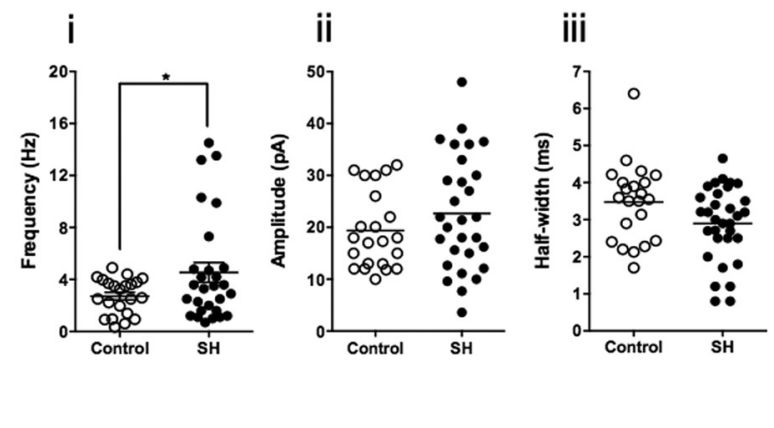

F

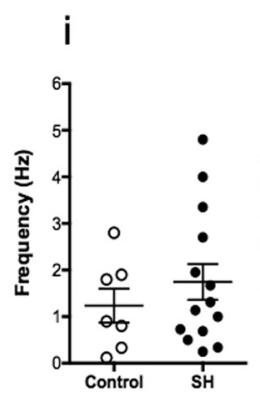

iii

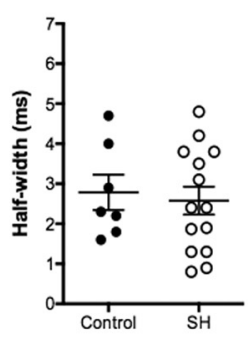

Figure 8. Spontaneous currents are increased in nonlabeled NTS neurons from SH rats. $\boldsymbol{A}$, Representative traces of spontaneous currents in NTS neuron from control and SH rat. $\boldsymbol{B}$, Average of frequency (Bi), amplitude (Bii), and half-width (Biii) of spontaneous currents in NTS neuron from control and SH rats. C, Representative traces of spontaneous excitatory currents in NTS neuron from control and SH rat. D, Average of frequency (Di), amplitude (Dii), and half-width (Diii) of spontaneous excitatory currents in NTS neuron from control and SH animals. $\boldsymbol{E}$, Representative traces of miniature spontaneous excitatory currents in NTS neuron from control and SH rats. $\boldsymbol{F}$, Average of frequency (Fi), amplitude (Fii), and half-width (Fiii) of miniature spontaneous excitatory currents in NTS neuron from control and SH rats; ${ }^{*} p<0.05$, unpaired $t$ test.

receptors, demonstrating that labeled NTS neurons also presented a $\mathrm{IK}_{\mathrm{A}}$ reduction after $\mathrm{SH}$.

The $\mathrm{IK}_{\mathrm{A}}$ decreases the spontaneous firing, finely modulates the action potential threshold and interspike intervals (Li et al., 2006; Cai et al., 2007) and it was previously described in NTS neurons, mainly in inhibitory interneurons of NTS and baroreceptor second-order NTS neurons receiving C-fiber afferent inputs (Dekin and Getting, 1987; Dekin et al., 1987; Moak and Kunze, 1993; Paton et al., 1993; Tell and Bradley, 1994; Sundaram et al., 1997; Butcher and Paton, 1998; Bailey et al., 2002; Uteshev and Smith, 2006; Suwabe and Bradley, 2009). Our results demonstrated that SH decreases the $\mathrm{IK}_{\mathrm{A}}$ in NTS neurons and consequently may facilitate the occurrence of the observed highfrequency of action potentials.

The mechanisms underlying the $\mathrm{IK}_{\mathrm{A}}$ reduction after $\mathrm{SH}$ are not known, but recently Naskar and Stern (2014) demonstrated that $\mathrm{IK}_{\mathrm{A}}$ is reduced in hypothalamic magnocellular neurosecretory neurons after astrocytic inhibition. The au- thors showed that during dehydration, a condition known to produce a retraction of astrocytic process, the astrocytic glutamate GLT1 transporter was blunted, resulting in an abnormal increase in glutamate levels at the synaptic cleft. The endogenous extracellular glutamate activates extra-synaptic NMDA receptors, which leads to inhibition of $\mathrm{IK}_{\mathrm{A}}$, in a $\mathrm{Ca}^{2+}$ and protein kinase $\mathrm{C}$-dependent manner. To test the possibility that astrocyte can also modulate the $\mathrm{IK}_{\mathrm{A}}$ in our experiments, we incubated the NTS slices with FAC, a glial metabolism inhibitor (Fonnum et al., 1997). FAC decreased $\mathrm{IK}_{\mathrm{A}}$ in nonlabeled NTS neurons from control rats, but surprisingly produced no change in $\mathrm{IK}_{\mathrm{A}}$ amplitude of $\mathrm{SH}$ rats, suggesting that $\mathrm{SH}$ exposure affects the functional coupling between astrocytes and intrinsic properties of NTS neurons, but the mechanisms underlying this effect of $\mathrm{SH}$ on astrocytes remain to be evaluated.

We must also consider the possibility that $\mathrm{SH}$ affects the subunits that constitute the potassium channels or even a decrease in 
the number of channels mediating IKA in NTS neurons. Voltagedependent potassium channels subunits are divided in eight subfamilies (Coetzee et al., 1999) and channels containing Kv3.4 subunits mediate $\mathrm{IK}_{\mathrm{A}}$, which are downregulated by chronic hypoxia in glomus cells of the carotid body (Kääb et al., 2005). Considering that NTS presented high immunoreactivity for Kv3.4 subunit (Brooke et al., 2004), we suggest that SH decreases the Kv3.4 expression, reducing the channel conductance and increasing the excitability of NTS neurons. Such substantial difference in $\mathrm{IK}_{\mathrm{A}}$ between NTS neurons from control and SH rats may impact on the ability of afferent synaptic inputs to excite the postsynaptic neurons during SH. Moreover, the enhanced excitability of NTS neurons can be also related to an increase in the excitatory transmission and for this reason, we evaluated the synaptic transmission of NTS neurons. For this purpose, we stimulated TS afferent fibers and recorded the action potential in NTS neurons. In fact, the percentage of failure to induce action potential in $\mathrm{SH}$ rats (18\%) was reduced compared with the control group (53\%), indicating that after $\mathrm{SH}$ the inputs stimulation are much more efficient to produce action potential.

To clarify the mechanisms involved in TS-evoked discharge, we analyzed the synaptic currents as a parameter of evoked transmission in SH rats. The data show that TS-evoked currents in NTS neuron from SH rats presented higher amplitude compared with those from control rats, indicating that $\mathrm{SH}$ also affects the synaptic currents in nonlabeled NTS neurons. In accordance with the analysis of synaptic plasticity (comparison of $1 / C V^{2}$ and synaptic depression protocol) we are assuming that its effect is not on afferent fibers. It is important to note that $\mathrm{SH}$ can affect astrocytes or even the recorded neuron. On the other hand, chronic $\mathrm{SH}(7 \mathrm{~d})$ produces changes in both presynaptic and postsynaptic mechanisms, with consequent increase in the amplitude of TS-evoked current in NTS neurons (Zhang et al., 2009). In this context, previous study from our laboratory described that $\mathrm{CIH}$ during $10 \mathrm{~d}$ decreased the TS-evoked currents in NTS neurons (Almado et al., 2012) and suggested that the $\mathrm{CIH}$-induced synaptic depression was due to the reduction in the number of active synapses. Therefore, the duration of hypoxia may activate different mechanisms affecting the synaptic transmission, contributing to changes in the excitability of neurons.

In the present study we also evaluated the spontaneous currents, an index of basal neurotransmission, and interestingly $\mathrm{SH}$ increased the frequency of total (inhibitory and excitatory currents) and excitatory spontaneous currents, with no change in amplitude or half-width of events, indicating that $\mathrm{SH}$ affected the spontaneous transmission by presynaptic mechanisms. These changes in spontaneous transmission are action-potential dependent, because there is no difference in mSEPSCs in NTS neurons from control or SH rats. In this regard, SH clearly induces a facilitatory effect on the spontaneous glutamatergic neurotransmission in the NTS.

We conclude that exposure to short-term SH increases the autonomic and respiratory responses of chemoreflexes and baroreflexes, probably due to the increased excitation at the second order NTS neurons associated to: (1) reduction in $\mathrm{IK}_{\mathrm{A}}$ consequent to a decrease in astrocytic modulation and (2) an increase in spontaneous excitatory synaptic transmission.

\section{References}

Abdala AP, McBryde FD, Marina N, Hendy EB, Engelman ZJ, Fudim M, Sobotka PA, Gourine AV, Paton JF (2012) Hypertension is critically dependent on the carotid body input in the spontaneously hypertensive rat. J Physiol 590:4269-4277. CrossRef Medline
Accorsi-Mendonça D, Bonagamba LG, Leão RM, Machado BH (2009) Are L-glutamate and ATP cotransmitters of the peripheral chemoreflex in the rat nucleus tractus solitarius? Exp Physiol 94:38-45. CrossRef Medline

Accorsi-Mendonça D, Castania JA, Bonagamba LG, Machado BH, Leão RM (2011) Synaptic profile of nucleus tractus solitarius neurons involved with the peripheral chemoreflex pathways. Neuroscience 197:107-120. CrossRef Medline

Accorsi-Mendonça D, Machado BH (2013) Synaptic transmission of baroand chemoreceptors afferents in the NTS second order neurons. Auton Neurosci 175:3-8. CrossRef Medline

Accorsi-Mendonça D, Leão RM, Aguiar JF, Varanda WA, Machado BH (2007) Urethane inhibits the GABAergic neurotransmission in the nucleus of the solitary tract of rat brain stem slices. Am J Physiol Regul Integr Comp Physiol 292:R396-R402. CrossRef Medline

Almado CE, Machado BH, Leão RM (2012) Chronic intermittent hypoxia depresses afferent neurotransmission in NTS neurons by a reduction in the number of active synapses. J Neurosci 32:16736-16746. CrossRef Medline

Antunes VR, Braga VA, Machado BH (2005) Autonomic and respiratory responses to microinjection of ATP into the intermediate or caudal nucleus tractus solitarius in the working heart-brainstem preparation of the rat. Clin Exp Pharmacol Physiol 32:467-472. CrossRef Medline

Baekey DM, Dick TE, Paton JF (2008) Pontomedullary transection attenuates central respiratory modulation of sympathetic discharge, heart rate and the baroreceptor reflex in the in situ rat preparation. Exp Physiol 93:803-816. CrossRef Medline

Bailey TW, Jin YH, Doyle MW, Andresen MC (2002) Vanilloid-sensitive afferents activate neurons with prominent A-type potassium currents in nucleus tractus solitarius. J Neurosci 22:8230-8237. Medline

Barraco R, el-Ridi M, Ergene E, Parizon M, Bradley D (1992) An atlas of the rat subpostremal nucleus tractus solitarius. Brain Res Bull 29:703-765. Medline

Basu CK, Selvamurthy W, Bhaumick G, Gautam RK, Sawhney RC (1996) Respiratory changes during initial days of acclimatization to increasing altitudes. Aviat Space Environ Med 67:40-45. Medline

Bekkers JM, Stevens CF (1990) Presynaptic mechanism for long-term potentiation in the hippocampus. Nature 346:724-729. CrossRef Medline

Brooke RE, Atkinson L, Batten TF, Deuchars SA, Deuchars J (2004) Association of potassium channel Kv3.4 subunits with pre- and post-synaptic structures in brainstem and spinal cord. Neuroscience 126:1001-1010. CrossRef Medline

Brophy S, Ford TW, Carey M, Jones JF (1999) Activity of aortic chemoreceptors in the anaesthetized rat. J Physiol 514:821-828. CrossRef Medline

Butcher JW, Paton JF (1998) K+ channel blockade in the NTS alters efficacy of two cardiorespiratory reflexes in vivo. Am J Physiol 274:R677-R685. Medline

Cai SQ, Li W, Sesti F (2007) Multiple modes of a-type potassium current regulation. Curr Pharm Des 13:3178-3184. CrossRef Medline

Calbet JA (2003) Chronic hypoxia increases blood pressure and noradrenaline spillover in healthy humans. J Physiol 551:379-386. CrossRef Medline

Chen CY, Horowitz JM, Bonham AC (1999) A presynaptic mechanism contributes to depression of autonomic signal transmission in NTS. Am J Physiol 277:H1350-H1360. Medline

Chitravanshi VC, Sapru HN (1995) Chemoreceptor-sensitive neurons in commissural subnucleus of nucleus tractus solitarius of the rat. Am J Physiol 268:R851-R858. Medline

Claps A, Torrealba F (1988) The carotid body connections: a WGA-HRP study in the cat. Brain Res 455:123-133. CrossRef Medline

Coetzee WA, Amarillo Y, Chiu J, Chow A, Lau D, McCormack T, Moreno H, Nadal MS, Ozaita A, Pountney D, Saganich M, Vega-Saenz de Miera E, Rudy B (1999) Molecular diversity of K+ channels. Ann N Y Acad Sci 868:233-285. CrossRef Medline

Contreras RJ, Beckstead RM, Norgren R (1982) The central projections of the trigeminal, facial, glossopharyngeal and vagus nerves: an autoradiographic study in the rat. J Auton Nerv Syst 6:303-322. Medline

Dekin MS, Getting PA (1987) In vitro characterization of neurons in the ventral part of the nucleus tractus solitarius: II. Ionic basis for repetitive firing patterns. J Neurophysiol 58:215-229. Medline

Dekin MS, Getting PA, Johnson SM (1987) In vitro characterization of neurons in the ventral part of the nucleus tractus solitarius: I. Identification of 
neuronal types and repetitive firing properties. J Neurophysiol 58:195214. Medline

Donoghue S, Felder RB, Jordan D, Spyer KM (1984) The central projections of carotid baroreceptors and chemoreceptors in the cat: a neurophysiological study. J Physiol 347:397-409. CrossRef Medline

Doyle MW, Andresen MC (2001) Reliability of monosynaptic sensory transmission in brain stem neurons in vitro. J Neurophysiol 85:22132223. Medline

Finley JC, Katz DM (1992) The central organization of carotid body afferent projections to the brainstem of the rat. Brain Res 572:108-116. CrossRef Medline

Fonnum F, Johnsen A, Hassel B (1997) Use of fluorocitrate and fluoroacetate in the study of brain metabolism. Glia 21:106-113. CrossRef Medline

Glaum SR, Miller RJ (1995) Presynaptic metabotropic glutamate receptors modulate omega-conotoxin-GVIA-insensitive calcium channels in the rat medulla. Neuropharmacology 34:953-964. CrossRef Medline

Hackett PH, Roach RC (2001) High-altitude illness. N Engl J Med 345:107114. CrossRef Medline

Head GA, Adams MA (1988) Time course of changes in baroreceptor reflex control of heart rate in conscious SHR and WKY: contribution of the cardiac vagus and sympathetic nerves. Clin Exp Pharmacol Physiol 15: 289-292. CrossRef Medline

Kääb S, Miguel-Velado E, López-López JR, Pérez-García MT (2005) Down regulation of Kv3.4 channels by chronic hypoxia increases acute oxygen sensitivity in rabbit carotid body. J Physiol 566:395-408. CrossRef Medline

Lancaster B, Nicoll RA (1997) Properties of two calcium-activated hyperpolarizations in rat hippocampal neurones. J Physiol 389:187-203. CrossRef Medline

Li Q, Bi HR, Zhang R, Zhu DL (2006) Kv3.4 channel is involved in rat pulmonary vasoconstriction induced by 15-hydroxyeicosatetraenoic acid. Sheng Li Xue Bao 58:77-82. Medline

Liu X, He L, Dinger B, Stensaas L, Fidone S (2013) Sustained exposure to cytokines and hypoxia enhances excitability of oxygen-sensitive type I cells in rat carotid body: correlation with the expression of HIF- $1 \alpha$ protein and adrenomedullin. High Alt Med Biol 14:53-60. CrossRef Medline

Machado BH (2001) Neurotransmission of the cardiovascular reflexes in the nucleus tractus solitarii of awake rats. Ann N Y Acad Sci 940:179-196. CrossRef Medline

Machado BH (2004) Chemoreflex and sympathoexcitation. In: Neural mechanisms of cardiovascular regulation (Dun NJ, Machado BH, Pilowsky PM, eds), pp 59-80. Boston: Kluwer Academic.

Madison DV, Nicoll RA (1984) Control of the repetitive discharge of rat CA 1 pyramidal neurones in vitro. J Physiol 354:319-331. CrossRef Medline

Malinow R, Tsien RW (1990) Presynaptic enhancement shown by wholecell recordings of long-term potentiation in hippocampal slices. Nature 346:177-180. CrossRef Medline

Marcus NJ, Del Rio R, Schultz EP, Xia XH, Schultz HD (2014) Carotid body denervation improves autonomic and cardiac function and attenuates disordered breathing in congestive heart failure. J Physiol 592:391-408. CrossRef Medline

Mathie A, Wooltorton JR, Watkins CS (1998) Voltage-activated potassium channels in mammalian neurons and their block by novel pharmacological agents. Gen Pharmacol 30:13-24. CrossRef Medline

McBryde FD, Abdala AP, Hendy EB, Pijacka W, Marvar P, Moraes DJ, Sobotka PA, Paton JF (2013) The carotid body as a putative therapeutic target for the treatment of neurogenic hypertension. Nat Commun 4:2395. CrossRef Medline

McDonald DM (1983) Morphology of the rat carotid sinus nerve: I. Course, connections, dimensions and ultrastructure. J Neurocytol 12:345-372. CrossRef Medline

Mendelowitz D, Yang M, Andresen MC, Kunze DL (1992) Localization and retention in vitro of fluorescently labeled aortic baroreceptor terminals on neurons from the nucleus tractus solitarius. Brain Res 581:339-343. CrossRef Medline

Mifflin SW (1992) Arterial chemoreceptor input to nucleus tractus solitarius. Am J Physiol 263:R368-R375. Medline

Miles R (1986) Frequency dependence of synaptic transmission in nucleus of the solitary tract in vitro. J Neurophysiol 55:1076-1090. Medline

Moak JP, Kunze DL (1993) Potassium currents of neurons isolated from medical nucleus tractus solitarius. Am J Physiol 265:H1596-H602. Medline

Moraes DJ, Bonagamba LG, Costa KM, Costa-Silva JH, Zoccal DB, Machado BH (2014) Short-term sustained hypoxia induces changes in the coupling of sympathetic and respiratory activities in rats. J Physiol 592:20132033. CrossRef Medline

Moraes DJ, Bonagamba LG, Zoccal DB, Machado BH (2011) Modulation of respiratory responses to chemoreflex activation by L-glutamate and ATP in the rostral ventrolateral medulla of awake rats. Am J Physiol Regul Integr Comp Physiol 300:R1476-R1486. CrossRef Medline

Moraes DJ, Zoccal DB, Machado BH (2012) Sympathoexcitation during chemoreflex active expiration is mediated by L-glutamate in the RVLM/ Bötzinger complex of rats. J Neurophysiol 108:610-623. CrossRef Medline

Moraes DJ, da Silva MP, Bonagamba LG, Mecawi AS, Zoccal DB, AntunesRodrigues J, Varanda WA, Machado BH (2013) Electrophysiological properties of rostral ventrolateral medulla presympathetic neurons modulated by the respiratory network in rats. J Neurosci 33:19223-19237. CrossRef Medline

Naskar K, Stern JE (2014) A functional coupling between extrasynaptic NMDA receptors and A-type $\mathrm{K}+$ channels under astrocyte control regulates hypothalamic neurosecretory neuronal activity. J Physiol 592:28132827. CrossRef Medline

Neher E, Sakaba T (2001) Estimating transmitter release rates from postsynaptic current fluctuations. J Neurosci 21:9638-9654. Medline

Ortega-Sáenz P, Pardal R, Levitsky K, Villadiego J, Muñoz-Manchado AB, Durán R, Bonilla-Henao V, Arias-Mayenco I, Sobrino V, Ordóñez A, Oliver M, Toledo-Aral JJ, López-Barneo J (2013) Cellular properties and chemosensory responses of the human carotid body. J Physiol 591: 6157-6173. CrossRef Medline

Ortiz F, Iturriaga R, Varas R (2009) Sustained hypoxia enhances TASK-like current inhibition by acute hypoxia in rat carotid body type-I cells. Adv Exp Med Biol 648:83-88. CrossRef Medline

Paton JF (1996) A working heart-brainstem preparation of the mouse. J Neurosci Methods 65:63-68. CrossRef Medline

Paton JF, Foster WR, Schwaber JS (1993) Characteristic firing behavior of cell types in the cardiorespiratory region of the nucleus tractus solitarii of the rat. Brain Res 604:112-125. CrossRef Medline

Paton JF, Boscan P, Pickering AE, Nalivaiko E (2005) The yin and yang of cardiac autonomic control: vago-sympathetic interactions revisited. Brain Res Brain Res Rev 49:555-565. CrossRef Medline

Paton JF, Ratcliffe L, Hering D, Wolf J, Sobotka PA, Narkiewicz K (2013) Revelations about carotid body function through its pathological role in resistant hypertension. Curr Hypertens Rep 15:273-280. CrossRef Medline

Pongs O (1999) Voltage-gated potassium channels: from hyperexcitability to excitement. FEBS Lett 452:31-35. CrossRef Medline

Roach RC, Hackett PH (2001) Frontiers of hypoxia research: acute mountain sickness. J Exp Biol 204:3161-3170. Medline

Scheuer DA, Zhang J, Toney GM, Mifflin SW (1996) Temporal processing of aortic nerve evoked activity in the nucleus of the solitary tract. J Neurophysiol 76:3750-3757. Medline

Schild JH, Clark JW, Canavier CC, Kunze DL, Andresen MC (1995) Afferent synaptic drive of rat medial nucleus tractus solitarius neurons: dynamic simulation of graded vesicular mobilization, release, and non-NMDA receptor kinetics. J Neurophysiol 74:1529-1548. Medline

Seiders EP, Stuesse SL (1984) A horseradish peroxidase investigation of carotid sinus nerve components in the rat. Neurosci Lett 46:13-18. CrossRef Medline

Storm JF (1987) Action potential repolarization and a fast afterhyperpolarization in rat hippocampal pyramidal cells. J Physiol 385:733759. CrossRef Medline

Sundaram K, Johnson SM, Felder RB (1997) Altered expression of delayed excitation in medial NTS neurons of spontaneously hypertensive rats. Neurosci Lett 225:205-209. CrossRef Medline

Suwabe T, Bradley RM (2009) Characteristics of rostral solitary tract nucleus neurons with identified afferent connections that project to the parabrachial nucleus in rats. J Neurophysiol 102:546-555. CrossRef Medline

Tamisier R, Anand A, Nieto LM, Cunnington D, Weiss JW (2005) Arterial pressure and muscle sympathetic nerve activity are increased after two 
hours of sustained but not cyclic hypoxia in healthy humans. J Appl Physiol 98:343-349. Medline

Tell F, Bradley RM (1994) Whole-cell analysis of ionic currents underlying the firing pattern of neurons in the gustatory zone of the nucleus tractus solitarii. J Neurophysiol 71:479-492. Medline

Uteshev VV, Smith DV (2006) Cholinergic modulation of neurons in the gustatory region of the nucleus of the solitary tract. Brain Res 1084:38-53. CrossRef Medline

Wang ZY, Baker TL, Keith IM, Mitchell GS, Bisgard GE (2000) Continuous, but not episodic hypoxia, induces CREB phosphorylation in rat carotid body type I cells. Adv Exp Med Biol 475:631-635. Medline

Zhang W, Carreño FR, Cunningham JT, Mifflin SW (2008) Chronic sustained and intermittent hypoxia reduce function of ATP-sensitive potassium channels in nucleus of the solitary tract. Am J Physiol Regul Integr Comp Physiol 295:R1555-R1562. CrossRef Medline

Zhang W, Carreño FR, Cunningham JT, Mifflin SW (2009) Chronic sustained hypoxia enhances both evoked EPSCs and norepinephrine inhibition of glutamatergic afferent inputs in the nucleus of the solitary tract. J Neurosci 29:3093-3102. CrossRef Medline

Zoccal DB, Bonagamba LG, Paton JF, Machado BH (2009) Sympatheticmediated hypertension of awake juvenile rats submitted to chronic intermittent hypoxia is not linked to baroreflex dysfunction. Exp Physiol 94: 972-983. CrossRef Medline

Zucker RS, Regehr WG (2002) Short-term synaptic plasticity. Annu Rev Physiol 64:355-405. CrossRef Medline 